TITLE:

\title{
Axial length and outcomes of macular hole surgery assessed by spectral-domain optical coherence tomography.
}

\section{$\operatorname{AUTHOR}(\mathrm{S}):$}

Suda, Kenji; Hangai, Masanori; Yoshimura, Nagahisa

\section{CITATION:}

Suda, Kenji ...[et al]. Axial length and outcomes of macular hole surgery assessed by spectral-domain optical coherence tomography.. American journal of ophthalmology 2011, 151(1): 118-127.e1

ISSUE DATE:

2011-01

URL:

http://hdl.handle.net/2433/134597

\section{RIGHT:}

@ 2011 Elsevier Inc.; この論文は出版社版でありません。引用の際には 出版社版をご確認ご利用ください。; This is not the published version. Please cite only the published version. 


\section{Elsevier Editorial System(tm) for American Journal of Ophthalmology Manuscript Draft}

Manuscript Number: AJ0-10-155R1

Title: Axial Length and Outcomes of Macular Hole Surgery Assessed by Spectral-Domain Optical Coherence Tomography

Article Type: Original Article

Keywords: axial length; macular hole surgery; retinoschisis; pars plana vitrectomy; spectral-domain optical coherence tomography

Corresponding Author: Masanori Hangai, M.D.

Corresponding Author's Institution: Kyoto University Graduate School of Medicine

First Author: Kenj Suda, M.D.

Order of Authors: Kenj Suda, M.D.; Masanori Hangai, M.D.; Nagahisa Yoshimura, M.D. 
Axial length and outcome of macular hole surgery. Suda K, et al.

\section{ABSTRACT $(\underline{237} / 250$ words $)$}

PURPOSE: To use spectral-domain optical coherence tomography (SD-OCT) to evaluate macular hole surgery outcomes and features predicting anatomical failure.

DESIGN: Retrospective interventional case series.

METHODS: Fifty-two eyes of 50 consecutive patients with macular holes were examined. All eyes underwent 3-port pars plana vitrectomy with internal limiting membrane peeling. Eyes were examined postoperatively by dense serial SD-OCT scanning over the macula.

RESULTS: Eyes with initial anatomical failure were significantly more likely to have greater axial length and refractive error and more posterior staphyloma compared to eyes with initial anatomical success $(P=0.031-0.0060,<0.0001)$. Overall initial and final anatomical success rates were $92.3 \%$ (48 of 52 eyes). In highly myopic eyes with axial lengths $\geq 26.0 \mathrm{~mm}$, initial and final success rates were $73.3 \%$ ( 11 of 15 eyes) compared to $100.0 \%$ (37 of 37 eyes) of eyes with axial lengths $<26.0 \mathrm{~mm}(P=0.0050)$. In highly myopic eyes, initial and final success rates were $0 \%$ ( 0 of 3 eyes) of eyes with axial lengths $\geq 30.0 \mathrm{~mm}$ compared to $91.7 \%$ ( 11 of 12 eyes) of eyes with axial lengths $\geq 26.0 \mathrm{~mm}$ and $<$ $30.0 \mathrm{~mm}(P<0.0001)$. "Retinoschisis-like" thickening of the outer retina was seen in $3(75.0 \%)$ of 4 eyes with initial failure compared to $3(6.3 \%)$ of 48 eyes with initial success $(P=0.0030)$.

CONCLUSIONS: Axial length $\geq 30.0 \mathrm{~mm}$ may increase the risk of anatomical failure of macular hole surgery. 
July 6, 2010

Thomas J. Liesegang, MD

Editor-in-Chief

American Journal of Ophthalmology

Mayo Clinic

4500 San Pablo Road

Jacksonville, FL 32224-1865

USA

Re: AJO-10-155, "Axial Length and Outcomes of Macular Hole Surgery Assessed by Spectral-Domain Optical Coherence Tomography"

Dear Dr. Liesegang:

We thank you for reviewing our manuscript and for forwarding the enlightening comments. We appreciate the constructive suggestions of the reviewers and the Editor; these suggestions have helped us revise our manuscript. After carefully considering all of the raised points, we have revised our manuscript accordingly. We believe that we have addressed all of the comments, as mentioned in the list below. I attest that all coauthors of this manuscript (Kenji Suda, Masanori Hangai, and Nagahisa Yoshihisa) have seen and agree with all the changes made to the manuscript. We hope that you will find our revised manuscript suitable for publication in the American Journal of Ophthalmology.

Sincerely yours,

Masanori Hangai, MD

Associate Professor

Department of Ophthalmology and Visual Sciences

Kyoto University Graduate School of Medicine

Kyoto, Japan 


\section{Axial length and macular hole surgery. Suda K, et al.-Page 1}

\section{【Comment \#1】}

A problem is the analysis of the data. The statistical analysis and grouping of the results needs to be significantly revised. From Table 3 and Figure 1, it appears that $100 \%$ of patients with axial length of $30 \mathrm{~mm}$ or higher had macular holes that failed to close. These patients appear to be clearly different from the rest of the group.

\section{【Response to Comment \#1】}

Thank you for the enlightening comment.

We agree that we need to revise the statistical analysis and grouping of the results because all eyes with axial lengths $\geq 30 \mathrm{~mm}$ had macular holes that failed to close after surgery. In the revised manuscript, we have divided the highly myopic eyes with axial length $\geq 26 \mathrm{~mm}$ into eyes with axial lengths $\geq 30 \mathrm{~mm}$ (Group 1) and eyes with axial lengths 26-30 mm (Group 2) and then performed statistical analyses (Kruskal Wallis $\mathrm{H}$-test for continuous data and Fisher's exact test for categorical data) as shown in the revised Table 1. As a result, all eyes with axial lengths $<26 \mathrm{~mm}$ had macular holes that successfully closed after the initial surgery, $91.7 \%$ of eyes with axial lengths $26-30 \mathrm{~mm}$ had macular holes that successfully closed after the initial surgery, and no eyes with axial lengths $\geq$ $30 \mathrm{~mm}$ had macular holes that successfully closed after the initial surgery. As suggested, this grouping successfully shows that the eyes with axial lengths $\geq$ $30 \mathrm{~mm}$ are clearly different from the other groups.

According to this grouping by axial length, we have revised Table 1 and the corresponding descriptions in the Results section of the revised manuscript (page 3, line 50-page 4, line 39; page 5, lines 37-40), and revised the Results section of the abstract. Here, we have re-arranged the order of data presentation as follows:

1. We have presented factors associated with initial success or initial failure of macular hole surgery prior to the presentation of outcomes and factors of macular hole surgery according to axial length with a new subheading, "Factors Associated with Initial Failure of Macular Hole Surgery" (page 3, lines 40-46 of the revised manuscript). Accordingly, we have re-numbered Table $2 \rightarrow$ Table 1 and Table $1 \rightarrow$ Table 2 .

2. We presented Figure 1 and then revised grouping of the study eyes into 3 groups based on axial length. These were addressed in the paragraph with a new 
Axial length and macular hole surgery. Suda $K$, et al._-Page 2

subheading, "Grouping According to Axial Length" (page 3, lines 50-Page 4, line 38 of the revised manuscript).

We have left the values for eyes with axial lengths $\geq 26 \mathrm{~mm}$ (Group $1+$ Group 2) because this appears to be a useful way to compare our results with those of other studies, which did not divide eyes with high myopia into 2 groups. We then conducted statistical analysis among the 3 groups as shown in the revised Table 1. According to the revision of the grouping of the statistical analysis and the results, we have extensively revised the Discussion section of the revised manuscript, particularly the first to third paragraphs (page 5, line 45-page 6 , line 46).

\section{【Comment \#2】}

Only 2 other patients in the entire series failed to close. One of them apparently had symptoms for 10 years. Macular holes of that duration have poor success rates, and this patient may be different enough that he should be left out of the study. The one remaining failure was a moderate myope with symptoms duration of "NA". It makes little sense to combine the moderate myopes with the high myopes based on this one failure.

\section{【Response to Comment \#2】}

We agree that we should remove the eye that had symptoms for 10 years and that moderate myopes and high myopes should not be combined based on the failure of this eye. We have removed that eye from the analysis and changed the axial length grouping so that moderate myopes and the high myopes are divided as addressed in the Response to Comment \#1. According to the exclusion, we have revised Table 1 (Group 3, Emmetropia/Mild Myopia/Hyperopia) and Table 2 (Initial Failure group) and the corresponding descriptions throughout the Results section (page 3, lines 32-37, 45-47, 51-54, 56, and 36; page 4, line 19, line 50, lines 56-58; page 5, lines 30-32), the Methods section (page 1, lines 54-56, and 33, page 2, lines 43-45), and Figure 1.

After we removed the eye that had symptoms for 10 years, we lost the statistical difference between any factors in multiple logistic regression analysis, so we removed the description related to multiple logistic regression analysis from the 
Methods, Results, and Discussion sections. We believe that, since the main finding of our study is that $75 \%$ of eyes with unsuccessful macular hole closure had axial lengths $\geq 30.0 \mathrm{~mm}$ (100\% of patients with axial lengths $\geq 30 \mathrm{~mm}$ had macular holes that failed to close) as pointed out by Comment \#1, this removal does not critically change our manuscript.

In addition, differences in mean macular hole sizes have lost statistical significance as shown in the revised Table 2.

\section{【Comment \#3】}

A conclusion from the data is that extremely long eyes (greater than $30 \mathrm{~mm}$ ) have poor success rates. For patients with duration of symptoms less than 1 year, and axial length of $29 \mathrm{~mm}$ or less, the success rate is close to or at 100 percent. To draw any other conclusion would require a much larger number of patients. Combining the moderate myopia group with the high myopia group confuses the picture, and is not supported by the data.

\section{【Response to Comment \#3】}

We agree that a conclusion from our data is that extremely long eyes ( $\geq 30 \mathrm{~mm}$ ) have poor success rates. We have extensively revised our manuscript based on dividing highly myopic eyes with axial length $\geq 26 \mathrm{~mm}$ into eyes with axial lengths $\geq 30 \mathrm{~mm}$ (Group 1) and eyes with axial lengths 26-30 mm (Group 2) as addressed in the response to Comment \#1. We then revised the conclusion in the last paragraph of the Discussion section of the revised manuscript (page 7 , lines 45-51) and the Conclusion section of the revised abstract.

【Comment \#4】 The finding of retinoschisis-like patterns in the OCTs is interesting. It may indicate differences in tractional forces in some patients who develop macular holes. Since many of these patients have high myopia, the axial length of the eye may play a role in the development of this pattern. This pattern may also be predictive of a lower success rate, but exploration of this point would require a larger number of patients.

\section{【Response to Comment \#4】}

Thank you for the comments with regard to the potential role of retinoschisis-like patterns in the OCTs in a lower success rate. We agree that we need a larger 
number of patients to explore the predictive role of this feature in macular hole surgical failure. On the other hand, too much discussion on retinoschisis-like patterns was pointed out by Comment \#7. According to these comments, we have revised the fourth, fifth, and sixth paragraphs of the original manuscript into the fourth and fifth paragraphs of the revised manuscript (page 6, lines 48- Page 7 , line 15). Here, we have simplified the discussion so that the clinical significance of this feature is clearly addressed without too much discussion. We have also added sentences to point out the sample size limitation (page 7, lines 8-10, and 15). We believe these revisions appropriately respond to Comment \#4 as well as to Comment \#7.

【Comment \#5】 A critical error in the paper is on page four, line one in which they state that the surgery is successful on eleven of thirteen eyes $(=73 \%)$. This is actually eleven of fifteen eyes (in thirteen patients). As they have stated it the data would not be statistically significant. The duration of follow-up is not noted. It apparently is relatively long since visions have recovered to a good level in many of the patients.

\section{【Response to Comment \#5】}

We apologize for the error in which the number of patients was shown instead of that of eyes. We have corrected the error on page 4, line 24 of the revised manuscript and on line 6 of the Results section of the revised abstract.

We are sorry that we did not describe the follow-up duration for visual acuity after surgery we used in our original manuscript. We used visual acuity at 6 months after the last surgery. We have added this description to the Results section (page 4, line 34 of the revised manuscript) and to Tables 1 and 2.

【Comment \#6】The authors state that they did multiple regression analysis and found no other factor except actual length with correlated with closure of the holes. However, one table indicates that duration of symptoms was 37.5 months in patients with initial failure in the non-closure group versus 3.1 months in patients with initial success in the closure group. It seems that this should be statistically significant depending on how the data is analyzed. 
Axial length and macular hole surgery. Suda $K$, et al._-Page 5

\section{【Response to Comment \#6】}

As suggested in Comment \#2, we have removed the eye that had symptoms for 10 years. We then re-calculated multiple logistic regression, and consequently found no factors that correlate with macular hole closure. Therefore, we have removed the description related to multiple logistic regression analysis from the Methods, Results, and Discussion sections as addressed in the response to Comment \#2. We believe that, since the main finding of our study is that $75 \%$ of eyes with unsuccessful macular hole closure had axial lengths $\geq 30.0 \mathrm{~mm}(100 \%$ of patients with axial lengths $\geq 30 \mathrm{~mm}$ had macular holes that failed to close) as pointed out by Comment \#1, this removal does not critically change our manuscript.

After we removed the eye in question, there were still significant preoperative differences between eyes with initial success and failure in mean axial length and whether there was posterior staphyloma but not in macular hole size. Refractive error became a significantly different factor between groups. These changes were incorporated into the Results section of the revised manuscript (page 3, lines 40-46), the revised abstract, and Table 1.

【Comment \#7】 There is a great deal of discussion about "retinoschisis like features". The authors are describing the generalized thickening of the retina which involves the outer retinal layers. Since the duration of symptoms is longer in patients with failure it may be that this finding correlates with duration rather than having a pathogenic meaning. Do not believe that the description of the retinoschisis like feature, an analysis of its assocation, or speculation on its causality is useful to the paper.

It may indicate differences in tractional forces in some patients who develop macular holes. Since many of these patients have high myopia, the axial length of the eye may play a role in the development of this pattern. This pattern may also be predictive of a lower success rate, but exploration of this point would require a larger number of patients.

\section{【Response to Comment \#7】}

We agree we included some inessential information regarding "retinoschisis-like" features. It is uncertain whether this finding correlates with axial length or symptom duration because symptom duration is also longer in eyes with failure 
Axial length and macular hole surgery. Suda K, et al._-Page 6

than eyes with success, although this difference was not statistically significant. We believe it has some meaning to point out the presence of this feature because it is possible that this feature may be associated with tractional forces in some patients who develop macular holes, longer axial length, and lower surgical success rate, as suggested in Comment \#4. In particular, higher resolution images created with enhanced SD-OCT may have been useful to visualize this features that had not been previously reported in eyes with macular holes. However, in order to discuss the significance of this feature in the pathogenesis of macular holes in eyes with high myopia and the surgical outcome of macular hole surgery, we would need a larger number of patients as pointed out by Comment \#4.

We have tried to just put emphasis on the presence of the "retinoschisis-like" features and have weakened our speculation of the role of this feature. We have removed much of the discussion regarding the comparison with macular retinoschisis (fourth paragraph of the original manuscript). We have also removed much of the discussion about the comparison of macular morphologies of highly myopic eyes with macular holes with those of typical idiopathic macular holes (fifth paragraph of the original manuscript). Consequently, we have just addressed that the "retinoschisis-like" features were found in some eyes, particularly in eyes with failure, and in eyes with severely high myopia (axial lengths $\geq 30.0 \mathrm{~mm}$ ). We have only pointed out the possibility that this feature may be associated with axial length and anatomical failure of macular hole surgeries. We did not point out the other possibility that this feature may be associated with symptom durations because we did not obtain statistical differences in symptom duration between eyes with failure and those with success. Finally, we concluded that we need a larger number of patients in order to confirm these speculations.

In summary, we have revised the fourth, fifth, and sixth paragraphs of the original manuscript into the fourth and fifth paragraphs of the revised manuscript.

We have not largely changed the seventh paragraph of the original manuscript that addressed speculations about possible remaining traction as a cause of anatomical failure of macular hole surgeries. Our main findings were that macular hole closure was unsuccessful in all highly myopic eyes with axial 
Axial length and macular hole surgery. Suda $K$, et al._Page 7

lengths $\geq 30.0 \mathrm{~mm}$ and our sub-findings were that eyes with initial anatomical failure were significantly more likely to have greater axial length, more posterior staphyloma, and more "retinoschisis-like" features compared to eyes with initial anatomical success. Readers will consider the reason why macular hole closure was unsuccessful in all highly myopic eyes with axial lengths $\geq 30.0 \mathrm{~mm}$.

Although our results did not provide strong evidence to answer to this question, our description of the speculative mechanisms underlining our finding would help to the readers' considerations.

We believe these revisions appropriately responded to both Comment \#7 and Comment \#4 (page 6, lines 48- Page 7, line 15 of the revised manuscript) and shortened the description of this feature.

\section{[Comment \#8】}

The paper could be considerably shortened.

\section{【Response to Comment \#8】}

We have tried to shorten the manuscript throughout. The total word count of the text has been reduced from 3,765 to 3,098.

The main deletions are as follows:

First, we have considerably shortened the fourth-sixth paragraphs of the Discussion section to respond to the above comments, particularly Comment \#4 and Comment \#7.

We have removed the first and third sentences of the paragraph subtitled "Posterior Staphyloma" (page 4, line 58-page 5, line 10 in the original manuscript). The first sentence has been removed because the same result was described in the page 3 , lines $45-47$ of the revised manuscript. The third sentence was removed because it does not appear to be useful for comparing eyes with retinoschisis-like features with or without posterior staphyloma in our small patient number. 
We have removed "The information collected retrospectively from each of the medical records included patient age and gender, duration of symptoms due to macular holes, axial length, preoperative refractive errors, preoperative and postoperative BCVA, size and stage of macular holes, presence or absence of posterior staphyloma, and surgical procedure." from the Methods section of the original manuscript (page 2, lines 23-31) because this data is shown in the Tables.

We have removed the phrases "The study was approved by the Institutional Review Board and Ethics Committee of Kyoto University Graduate School of Medicine. Informed consent was obtained from all patients." from the top of the Methods section of the original manuscript because these should be addressed in the Acknowledgments section. We have moved "All investigations adhered to the tenets of the Declaration of Helsinki." to the Acknowledgments section.

We have changed the description of axial lengths using symbols; ex. "axial length of $26.0 \mathrm{~mm}$ or more" $\rightarrow$ "axial length $\geq 26.00$ ".

\section{[Comment \#9】}

The AJO uses the AMA Style for references, which now included journal issue numbers.

\section{【Response to Comment \#9】}

We have included journal issue numbers for all the references according to the AMA Style. Thank you for bringing this to our notice.

\section{【Comment \#10】}

For each revision, the corresponding author must provide a statement that each of the coauthors has seen and agrees with each of the changes made to this manuscript in the revision and to the way his or her name is listed. It is not appropriate to add or remove authors at any time. Authors should only list their institutional affiliation at the time that they participated in the research; the corresponding author should additionally list his/her current address and email 
Axial length and macular hole surgery. Suda $K$, et al._-Page 9

for future correspondence.

【Response to Comment \#10】

I, the corresponding author, have confirmed that all co-authors of this manuscript (Kenji Suda, Masanori Hangai, and Nagahisa Yoshihisa) have seen and agree with all the changes made to the manuscript.

\section{[Comment \#11】}

Please ensure that all files intended for final publication are submitted to the office with each revision. If your final revision does not include all necessary files, those files will not be transmitted for publication. A common, and unacceptable, deficiency of many submissions is failure to refer to (call out) each figure, table and reference in the text. Please confirm that you have checked this function.

\section{【Response to Comment \#11】}

We have submitted all files intended for final publication to the office in this revision. We have ensured that each figure, table, and reference is cited in the text.

\section{[Comment \#12】}

Only one abstract should appear in your submission. Please make sure the corrected abstract is uploaded separately from the text and remove any extra copies of the abstract from the manuscript file. Please correct the Abstract if meaningful changes were made in the text during revision process.

\section{【Response to Comment \#12】}

We have uploaded the corrected abstract separately from the text. We corrected the abstract according to the changes made in the text during the revision process.

\section{【Comment \#13】}


The title page should also contain a suggested "short title" (limited to 45 characters) for your manuscript that will be included as footnote in the printed version. See the print journal for examples.

【Response to Comment \#13】

We have included a short title.

\section{【Comment \#14】}

The Journal requires that Clinical Trials be registered and the Acknowledgement Section should contain a statement about the registration location and number. Satisfactory public databases include the National Institute of Health maintained site at http://www.clinicaltrials.gov (for either NIH or non-NIH sponsored studies) or the International Standard Randomized Controlled Trials at http://www.controlled-trials.com.

【Response to Comment \#14】

Our study is not a Clinical Trial.

\section{【Comment \#15】}

For all human studies, please confirm that the Institutional Review Board (or similar body) statement and the Informed Consent statement for research is within the Acknowledgement section (see below). The authors are requested to confirm that they are in compliance with their Institutional Review Boards (IRBs) or similar authorities and HIPAA requirements; some IRBs require approval for even single case reports. In general, authors should not make the decision whether IRB approval is required; their IRB should make that determination. For animal studies, please confirm that the statement regarding the care of animals is within the Acknowledgement section. If this is a systematic evaluation of a treatment or a device ("research"), then IRB approval is required usually in a prospective manner. The AJO will not publish research on humans that does not have IRB approval. For clarification, see:

http://www.ijo.in/text.asp?2007/55/1/1/29486

【Response to Comment \#15】 
In the Acknowledgments section, we have stated that the Institutional Review Board approved this study and that an informed consent statement was obtained. We have also added a statement of adherence to the Declaration of Helsinki and all federal regulations in the Statement about Conformity with Author Information in the Acknowledgments section.

\section{【Comment \#16】}

The AJO requires enhanced disclosure information from the authors in a specific format. The following information should appear, in the order indicated (labeled $A$ through E), in the Acknowledgement section of the manuscript (just prior to the References). The information will appear in the print journal. This information should not appear on the Title page of the manuscript or in the Methods section of the manuscript.

a. Funding/Support (including none): any government and non-government support must be acknowledged. (The authors are reminded that several governments require providing open access to your manuscript.)

b. Financial Disclosures: now or in the previous two years that related to any commercial companies or devices (including none); employee, consultant or advisory positions; speaker bureaus, lecture fees; grant support, equity payments; patents; advisor to investment companies; and expert witness testimony. Financial involvement with companies that directly compete with products in this manuscript must also be disclosed. Do not try to determine yourself if your financial disclosures relate to the manuscript as that is for the editors and reader to determine.

c. Contributions to Authors in each of these areas: design and conduct of the study; collection, management, analysis, and interpretation of the data; and preparation, review, or approval of the manuscript. After each component, provide author initials in parentheses, SAMPLE: Contributions of Authors: Design of the study $(A B, C D, E F)$; Conduct of the study $(A B, E F, G H)$, etc. Each author must have a specific role in the manuscript. Overall management/supervision of a laboratory alone or a position of chairmanship alone does not constitute an authorship role. The AJO does not permit guest or honorary authorship. d. Statement about Conformity with Author Information: Name of IRB that approved the research or provide a statement and rationale as to why the named IRB waived approval, proper informed consent for both the treatment and 
participation in the research, HIPAA compliance, Clinical Trials registration, number and location, and Institutional Animal Care and Use Committee guidelines. If the IRB waived the need for approval of this research, then indicate adherence to the Declaration of Helsinki and all federal or state laws in your country. Authors cannot make the decision as to whether IRB approval is needed; your IRB should make that decision and provide a waiver if they feel it does not require IRB approval.

e. Other Acknowledgments: Statisticians and medical writers or industry writers might fulfill the criteria for authorship and should be recognized in that role.

Otherwise, recognize statistical consultation, medical writers or industry writers in the acknowledgment. Include the name and affiliation of the individual. The AJO does not accept manuscripts that do not accurately reflect who wrote the content i.e., the AJO does not permit ghost (hidden) authors. Editorial assistants, photographers, artists, laboratory associates, and others who simply assist in preparation of a manuscript are not to be acknowledged, however valuable their service. The Editor-in-Chief will permit limited exceptions. Because readers may infer endorsement of the data and conclusions, all persons must have given permission to be acknowledged and this must be confirmed in the cover letter.

\section{【Response to Comment \#16】}

We have disclosed all of the required information in the Acknowledgements section and added a description of adherence to the Declaration of Helsinki and all federal regulations in the Statement about Conformity with Author Information in the Acknowledgments section.

\section{【Comment \#17】}

FIGURE USAGE: The AJO's manuscript submission process is now an entirely digital process. Our system has an Artwork Quality Check function which will check your figures at the time of revision. Once the File Upload page is complete, click Next to run Artwork QC, which will provide results according to our print-quality guidelines. Simply click on the results to obtain feedback explaining any shortcomings on the figures and how to fix the problems. Authors should bear in mind, however, that the AJO standards for art as listed in the Author Instructions exceed those of this rudimentary artwork quality check tool and the authors are required to adhere to Author Information at AJO.com, despite 
assurances from this Artwork Quality Check. Please make all improvements prior to resubmission. The AJO Author Instructions has specific information regarding figure requirements, available at AJO.com.

【Response to Comment \#17】

We have prepared and uploaded our figures as suggested.

\section{[Comment \#18】}

For multi-part figures, each part of the figure should be submitted individually at the correct resolution and file type, labeled according to AJO style. You may additionally submit a composite figure in Word to indicate how you would wish the individual figure parts to be arranged upon publication. Please note that due to space restrictions, the publisher may not be able to use the provided layout, so it is imperative to also include any arrows, markings, and labels on the individually-submitted figures while maintaining the correct resolution, size, and file format. Alternatively, you may submit a composite figure only, at the correct resolution above with any appropriate arrows, markings, or labels, though the publisher may later request individual files if space does not permit use of the collage and publication could be delayed as a result.

\section{【Response to Comment \#18】}

We will submit only a composite figure at the correct resolution.

\section{[Comment \#19】}

If your manuscript was submitted with color figures, it is expected that the authors will pay for the color art that appears in the print issue. It is not appropriate to switch to black and white figures during a revision stage if the manuscript was peer reviewed with color figures. The Editor in Chief reserves the right to decide if Black and White figures are more appropriate in place of any color figures. See Author Information at AJO.com for more specific details concerning the costs.

\section{【Response to Comment \#19】}

We will pay for the color art. 


\section{Axial length and macular hole surgery. Suda K, et al.-Page 14}

\section{【Comment \#20】}

REFERENCES: PLEASE NOTE that the AJO style is identical to the AMA style and lists the first 6 authors; if more than 6 , then list the first 3 and then "et al." More information about AJO references is available in Author Information at AJO.com. At this revision stage, the Editor in Chief MAY REJECT a manuscript with incorrect AJO formatting of any of the references. The authors are SOLELY responsible for correct references; this service is not provided by the Journal copyeditors.

\section{【Response to Comment \#20】}

We have checked the accuracy of the references cited in our manuscript.

\section{[Comment \#21】}

The Corresponding Author is requested to provide a Table of Contents Statement (up to 75 words in length) that presents the content and clinical implications of the article for the Table of Contents of the Journal (see print copy of AJO). This statement should be on a separate page that contains the manuscript title and manuscript number. This is a stand-alone document from the manuscript and as such should not contain abbreviations or first-person pronouns (I, we).

[Response to Comment \#21】

We have provided a Table of Contents Statement as requested.

\section{【Comment \#22】}

Please confirm that your Discussion Section adheres to the following Author Information at AJO.com as appropriate for your manuscript: "Elucidate (but do not reiterate) the results, identify any statistically or clinically significant limitations or qualifications of the study, provide responses to other and contradictory literature, and state the conclusions that are directly supported by the data. Excessive generalization and undue speculation should be avoided. Give equal emphasis to positive and negative findings, state whether and what additional study is required, and conclude with the clinical applications or implications 
supported by the study. The conclusions are incorporated into the end of the discussion. Authors should avoid making statements on economic benefits and costs unless their manuscript includes economic data and analyses. Do not allude to work that has not been completed."

\section{【Response to Comment \#22】}

We have confirmed that our Discussion section adheres to the Author Information provided at AJO.com.

\section{【Comment \#23】}

AJO.com offers the opportunity to present additional data that cannot be published in the print issue, including additional illustrations and tables, videotapes of procedures, and animations. Supplemental Material must be submitted at the time of revision according to specifications, and such material may be edited.

Instructions for preparing supplemental material are listed at www.ajo.com/authorinfo under the "Accepted Manuscripts" sections. When uploading your supplemental material on the Attach Files page, please choose Multimedia Supplementary Materials for all parts and label each part (eg., Supplemental Figure Legend, Supplemental Figure 1, Supplemental video etc.). The legend for all Supplemental Material should also be uploaded as Multimedia Supplementary Materials. Each figure legend or table title must contain enough information so as to be able to be understood independent of the manuscript text (stand alone). If you are including supplemental material with your submission, please note the following on your manuscript title page: "Supplemental Material available at AJO.com" and also note, at the appropriate location in the manuscript and in parenthesis, "(Supplemental Material at AJO.com or Supplemental Figure 1)".

Once the article is accepted, the Supplemental Material will be forwarded by the AJO office to Dr Kaiser, the AJO Associate Editor supervising the Supplemental Material at AJO.com. You will be notified of its acceptance or requests for revisions.

【Response to Comment \#23】 
Axial length and macular hole surgery. Suda K, et al.-Page 16

Our manuscript does not include any supplemental material.

\section{【Comment \#24】}

The AJO seeks to further enhance recognition for the contributors of the scientific content in the Journal. Please provide a biographic sketch (limited to 75 words) from the first author (or both authors if there are only two) and a digital photo to be placed on the web site linked with the online version at www.ajo.com.

The digital photo should adhere to the following specifications:

Size -325 pixels by 500 pixels

Resolution -300 dpi

File format - .gif or .jpg

Head \& shoulders in a professional setting

There is no additional charge for color biophotos.

If there are more than two authors on the paper, the first photo and biosketch should be the first author and the second photo and biosketch should be determined by collective author agreement. Examples can be found on our Editorial Board page at http://www.ajo.com/content/ed board bios. Please do not use outline format. Include affiliations and the author's primary research interests. Upload these items into Editorial Manager under the appropriate heading along with your revised manuscript.

${ }^{* *}$ If you will be submitting a Biosketch and/or photo, it must be done at the time of revision.

【Response to Comment \#24】

We have provided a biographic sketch and digital photo of the first author.

\section{【Comment \#25】}

With revision, please provide a letter outlining your responses to each of these numbered items. You may copy and paste these comments into the Reviewer Response box during the revision upload process. Each of your responses should be given a number corresponding to the above items for ease of reference. 
Axial length and macular hole surgery. Suda K, et al.-Page 17

Also identify the page number and line in your revision where changes can be found.

\section{[Response to Comment \#25】}

We have provided our responses to each of the numbered items in this letter and have identified the page and line numbers in the revised manuscript where these changes can be found. 
Axial Length and Outcomes of Macular Hole Surgery Assessed by Spectral-Domain Optical Coherence Tomography

KENJI SUDA, MASANORI HANGAI, NAGAHISA YOSHIMURA

Department of Ophthalmology and Visual Sciences, Kyoto University Graduate School of Medicine, 54 Kawahara-cho, Shogoin, Sakyo-ku, Kyoto 606-8507, Japan

Running head: Axial Length and Macular Hole Surgery

Correspondence to Masanori Hangai, MD, Department of Ophthalmology and Visual Sciences, Kyoto University Graduate School of Medicine, 54 Kawahara-cho, Shogoin, Sakyo-ku, Kyoto 606-8507, Japan

Phone: +81-75-751-3259; Fax: +81-75-752-0933

E-mail: hangai@kuhp.kyoto-u.ac.jp 
Axial length and macular hole surgery. Suda K, et al.-_Page 1

\section{INTRODUCTION}

Based on the theory that vitreous traction is the cause of idiopathic macular holes, ${ }^{1-4}$ vitreoretinal surgery to relieve traction has become the established treatment and currently is highly successful for closing macular holes. ${ }^{5-10}$ In a pilot study reported in 1991, Kelly and Wendel ${ }^{5}$ achieved a $58 \%$ success rate for anatomical closure of full-thickness macular holes using pars plana vitrectomy (PPV) with posterior hyaloid peeling and intraocular gas tamponade. For surgery in which internal limiting membrane (ILM) peeling was also performed, primary closure rates of $76.4 \%$ to $100 \%$ have been reported. ${ }^{11}$

Shorter duration of symptoms, earlier stage or smaller size of the macular hole, better preoperative visual acuity, younger patient age, and male patient gender have been reported to be significantly associated with better surgical outcomes. ${ }^{7-9,12-18}$ However, consensus is lacking that high myopia/longer axial length is related to worse outcomes of macular hole surgery. ${ }^{19-22}$ Patel, et a ${ }^{19}$ reported a relatively low (60\%) closure rate for macular holes in highly myopic eyes, but in case-control studies, Sulkes, et $\mathrm{al}^{20}$ and Kobayashi, et $\mathrm{al}^{21}$ found no association between axial length and anatomical success of surgery. However, these studies did not use optical coherence tomography (OCT) to confirm closure of the macular hole, and it can be difficult to determine whether macular holes are closed by biomicroscopic examinations alone, especially in highly myopic eyes with choroidal atrophy, as shown by Coppe, et al, ${ }^{23}$ who detected macular holes by OCT in 24 of $383(6.26 \%)$ asymptomatic myopic eyes.

With more recently developed spectral-domain OCT (SD-OCT) technology, macular features can be visualized in great detail. ${ }^{24-27}$ Commercially available SD-OCT instruments acquire images 43 to 133 times faster than time-domain (Stratus) OCT instruments, which allows for acquisition of densely spaced serial B-scans that can be used to more precisely detect macular holes. High-speed image acquisition also allows averaging of multiple OCT B-scans at each location of interest on the retina, so as to reduce speckle noise and thus provide a detailed view of macular anatomy. ${ }^{28}$ In this study, we used SD-OCT to study the relationship between preoperative and postoperative factors and the success of macular hole surgery.

\section{METHODS}

\section{Patients}

Patient data were obtained by retrospective review of the medical records of $\underline{49}$ consecutive patients ( $\underline{52}$ eyes) who underwent surgery for macular hole at Kyoto University Hospital between February 2006 and July 2008. Candidates for the study were identified by review of the authors' surgical lists for the study period. The inclusion criteria for this study were as follows: 1) clinical 
presentation of macular hole; 2) treatment with conventional 20-gauge or 23-gauge three-port pars plana vitrectomy (PPV) with internal limiting membrane (ILM) peeling; and 3) a follow-up period of more than six months from the last intraocular surgery. Eyes were excluded from the study if they had preexisting ocular diseases or a history of ocular surgery, except for cataract surgery. Other exclusion criteria included 1) a history of treatment for peripheral retinal breaks before and after the primary surgery or 2) macular hole with retinal detachment.

All patients had undergone comprehensive ophthalmologic examinations before macular hole surgery, measurements of refractive errors (ARK-700A autorefractor, Nidek, Gamagori, Japan), measurements of uncorrected visual acuity (VA) and best-corrected visual acuity (BCVA) using the 5-meter Landolt chart, measurement of axial length using A-scan ultrasonography (UD-6000, TOMEY CORPORATION, Nagoya, Japan), slit-lamp examinations, measurements of intraocular pressure using a Goldmann applanation tonometer, and dilated indirect slit-lamp biomicroscopy.

The size of each macular hole before surgery was measured with reference to the diameter (approximately $150 \mu \mathrm{m}$ ) of the vein on the edge of the optic disc.

Conventional 20-gauge three-port PPV was performed in 10 eyes and 23-gauge transconjunctival PPV was performed in the other 43 eyes. A posterior vitreous detachment was created, followed by removal of the residual thin premacular posterior cortex. The peripheral vitreous was also excised. Triamcinolone acetonide was used intraoperatively to facilitate visualization of the vitreous and posterior hyaloid in all of the eyes in this study. ${ }^{29}$ All of the eyes underwent ILM peeling (3 to 4 disc diameters in size) with an ILM forceps, after staining with indocyanine green (ICG) or triamcinolone acetonide. ${ }^{11,30}$ In all eyes, fluid-air exchange was performed, followed by gas tamponade (instillation of $40 \mathrm{ml}$ of sulfur hexafluoride (SF6), 25\%). Patients were instructed to keep the head prone (face downwards) for at least 1 week postoperatively. In the $4 \underline{6}$ of $5 \underline{2}$ eyes that were phakic before macular hole surgery, phacoemulsification was performed before PPV, with implantation of an intraocular lens in all $4 \underline{6}$ eyes.

\section{Optical Coherence Tomography Examinations}

OCT examinations were performed by experienced ophthalmologists using time-domain OCT (Stratus) and/or SD-OCT (usually Spectralis ${ }^{\mathrm{TM}}$ HRA+OCT; Heidelberg Engineering, Heidelberg, Germany or occasionally RTVue-100; Optovue, Fremont, CA, USA). On preoperative scans of eyes with moderate cataract, time-domain (Stratus) OCT images tended to provide better information than SD-OCT scans.

SD-OCT only was used postoperatively. To determine whether the macular hole closed 
after surgery, dense serial SD-OCT scans were obtained over the macula; scanning was usually horizontal but sometimes vertical or radial. Initial anatomical success was defined as no visible open macular hole on any serial SD-OCT B-scans during the first month after the first macular hole surgery. To identify possible abnormalities in retinal microanatomy, so-called speckle-noise-reduced images were generated by averaging 20 to 50 SD-OCT B-scans obtained at each location of interest on the retina. ${ }^{28}$

\section{Statistical Analyses}

Statistical analyses were performed using SPSS version 17.0 (SPSS Inc, Chicago, IL, USA). The logarithm of the minimal angle of resolution (logMAR) was used for statistical analyses involving VA. For continuous values, the mean \pm standard deviation (SD) was calculated for each group and differences between 2 groups and 3 groups were evaluated for statistical significance by the Mann-Whitney U-test and the Kruskal Wallis H-test followed by Dunnett's rank test, respectively. Differences in categorical variables were evaluated for statistical significance by Fisher's exact test.

\section{RESULTS}

Fifty-two eyes of $\underline{49}$ patients ( $\underline{18}$ men, $\underline{31}$ women) with macular holes were included in this study. The $\underline{49}$ patients were $\underline{63.4 \pm 8.6}$ years old (range, 34 to 82 years) and the $5 \underline{2}$ eyes had a mean preoperative refractive error of $-3.0 \pm 5.2$ diopters (D) (range, 4.4 to $-18.5 \mathrm{D}$ ). The median preoperative BCVA (Snellen equivalent) for the $5 \underline{2}$ eyes was $20 / \underline{80}$ (range, 20/500 to 20/25).

\section{Factors Associated with Initial Failure of Macular Hole Surgery}

Table 1 shows the pre- and postoperative characteristics of eyes in which the initial surgery was a success or failure. There were significant preoperative differences between the groups in mean axial length $(\underline{P}<0.0001)$, refractive error $(0.031)$ and whether there was posterior staphyloma $(\underline{P}$ $=0.0060)$.

\section{Grouping According to Axial Length}

Mean axial length for the 52 eyes $(24.6 \pm 2.4 \mathrm{~mm}$; range, 21.1 to $31.9 \mathrm{~mm})$ was negatively correlated with age $(r=-0.44 \underline{7}, P=0.001$; Figure 1$)$ but positively correlated with refractive error $(r=-0.715, P=0.0001)$. Three $(60 \%)$ of 5 eyes with initial surgical failure were "outliers" on the linear regression curve (Fig 1). All 3 eyes had axial lengths $\geq 30.0 \mathrm{~mm}$. Accordingly, the $5 \underline{2}$ eyes were divided into 3 groups based on whether they had severely high myopia (Group 1), defined as an axial length $\geq 30.0 \mathrm{~mm}$, or moderately high myopia, defined as an axial length $\geq 26.0 \mathrm{~mm}$ 
and $<30.0 \mathrm{~mm}$ (Group 2), or mild myopia, emmetropia, or hyperopia (Group 3), defined as an axial length $\leq 26.0 \mathrm{~mm}$ (Table 2). Eyes were statistically significantly different among the $\underline{3}$ groups in mean age at onset of macular holes, mean axial length, mean preoperative refractive error, and in terms of the existence of posterior staphyloma (all, $P<\underline{0.0001}$ ) but not significantly different in patient gender, laterality, stage or size of macular hole, duration of symptoms, or preoperative logMAR BCVA (Table $\underline{2}$ ).

\section{Anatomical and Functional Success According to Axial Length}

The overall initial and final anatomical success rates of the macular hole surgeries were both $\underline{92.3} \%$ (48 of $5 \underline{2}$ eyes) (Table 2). The median final BCVA (Snellen equivalent) was 20/32 (range, $20 / 500$ to 20/12.5). In eyes with axial lengths $\leq 26.0 \mathrm{~mm}$, the initial and final success rates were both $100.0 \%$ (37 of $3 \underline{7}$ eyes), and in highly myopic eyes with axial lengths $\geq 26.0 \mathrm{~mm}$, the initial and final success rates were both $73.3 \%$ (11 of 15 eyes); this difference was significantly different (both, $P=0.0050$ ). In highly myopic eyes with axial lengths $\geq 30.0 \mathrm{~mm}$, the initial and overall success rates were both $0 \%$ ( 0 of 3 eyes), whereas in highly myopic eyes with axial lengths $\geq 26.0 \mathrm{~mm}$ and $<30.0 \mathrm{~mm}$, the initial and final success rates were both $91.7 \%$ (11 of 12 eyes). The initial and final success rates in eyes with axial lengths $\geq 30.0 \mathrm{~mm}$ were significantly lower than those in eyes with axial lengths $\geq 26.0 \mathrm{~mm}$ and $<30.0 \mathrm{~mm}$, and in eyes with axial lengths $<26.0 \mathrm{~mm}(P<0.0001$ for both) $($ Table 2$)$. At 6 months after the last surgery, the mean change in LogMAR of BCVA in eyes with axial lengths $\geq 30.0 \mathrm{~mm}$ was also significantly smaller than those in eyes with axial lengths $\geq 26.0 \mathrm{~mm}$ and $<30.0 \mathrm{~mm}(P=0.015)$ and in eyes with axial lengths $<26.0 \mathrm{~mm}(P=0.020)$ (Table 2$)$.

\section{Spectral-Domain Optical Coherence Tomography Findings}

On SD-OCT images obtained preoperatively, almost all eyes with all stages of macular holes (2, 3 , or 4) had centrifugal elevation of the retina limited to the fovea and cystoid spaces in the Henle nerve fiber layer, and sometimes in the inner nuclear layer, in the fovea or just outside the fovea (Fig 2). ${ }^{31,32}$

However, on preoperative SD-OCT images of $6(11 . \underline{5} \%)$ of the $5 \underline{2}$ eyes, a "retinoschisis-like" feature was seen, consisting of widespread thickening of the retina in the extrafoveal as well as foveal region (Figs 3 and 4). The thickening appeared to be located in the outer retina. The "retinoschisis-like" feature was seen in $3(6.3 \%)$ of 48 eyes with initial success and $3(\underline{75.0} \%)$ of $\underline{4}$ eyes with initial failure of macular hole surgery; this difference was statistically different (Table $\underline{1}, P=0.00 \underline{30}$ ). This "retinoschisis-like" feature was found to be associated with axial lengths (Table 2). In eyes with axial lengths $\geqq 26.0 \mathrm{~mm}$, the "retinoschisis-like" feature was 
seen in $3(75 \%)$ of the 4 eyes with initial failure, compared to only $1(9.1 \%)$ of 11 eyes with initial success (Table 3$)$; this difference was statistically different $(P=0.033)$.

Unexpectedly, the "retinoschisis-like" feature was also seen after macular hole surgery (Fig 3). Among the 15 eyes with axial lengths $\geqq 26.0 \mathrm{~mm}, 4$ had a flat open macular hole (failure of initial macular hole surgery but no "retinoschisis-like" feature, Fig 3) immediately after surgery, but 3 of these 4 developed a "retinoschisis-like" feature between 1 and 4 months after surgery; 2 of these 3 eyes had "retinoschisis-like" features before surgery (Table 3). A postoperative "retinoschisis-like" feature was also found in a significantly higher proportion of eyes with initial failure (3/4 eyes, $75 \%)$ than in eyes with initial success of surgery $(1 / 11$ eyes, $9.1 \% ; P=0.033)$.

\section{Posterior Staphyloma}

Among highly myopic eyes with axial lengths $\geqq 26.0 \mathrm{~mm}$, the difference in proportions with staphyloma and initial success (3 of 4 eyes) vs initial failure (3 of 11 eyes) was not statistically different $(P=0.24$; Table 3$)$.

\section{Reoperation}

A second operation was performed in $\underline{3}$ of $\underline{4}$ eyes with initial failure of macular hole surgery. Two of these $\underline{3}$ eyes had both posterior staphyloma and a "retinoschisis-like" feature, and retinal detachment occurred within the posterior staphyloma 1 to 2 months after the second surgery (Fig 4); the retina successfully reattached in one case, but not in the other case, after this second surgery, although the macular holes remained open in both eyes. The other eye that was reoperated upon had an axial length $\geqq 26.0 \mathrm{~mm}$ and $<30.0 \mathrm{~mm}$; the macular hole did not close after the second operation. No eye had reopening of the macular hole.

\section{DISCUSSION}

The main finding of our study was that macular hole closure was unsuccessful in all highly myopic eyes with axial lengths $\geq 30.0 \mathrm{~mm}$. Previous studies reported on relationships between initial success in macular hole surgery and factors such as symptom duration, the size or stage of the macular holes, or patient age or gender. ${ }^{12-18}$ However, findings are not consistent. In our study, greater axial length, higher refractive error, and the presence of posterior staphyloma were significantly associated with initial failure. Here, posterior staphyloma was found in all 3 eyes with axial lengths $\geq 30.0 \mathrm{~mm}$ and in the 4 successful eyes with axial lengths $<30.0 \mathrm{~mm}$. Thus, the axial length $\geq 30.0 \mathrm{~mm}$ appears to be most associated with unsuccessful macular hole closure.

This finding is likely to be responsible for the seemingly contradictory results between 

percentages of study eyes with axial lengths $\geq 30.0 \mathrm{~mm}$ may have affected the surgical closure rates in myopic eyes in those studies. Patel, et al ${ }^{19}$ reported a low rate of closure (60.0\%) of macular holes in patients with myopia of 6 diopters or greater. Sulkes, et $\mathrm{al}^{20}$ and Kobayashi, et $\mathrm{al}^{21}$ reported comparable rates of macular hole closure for eyes with "low" versus "high" myopia (92\% versus $81.0 \%$ and $92 \%$ versus $81.3 \%$, respectively). However, the percentages of study eyes with axial lengths $\geq 30.0 \mathrm{~mm}$ were not described in these studies. Grucia-Arumi, et $\mathrm{al}^{23}$ reported macular hole closure rate of $87.5 \%$ after surgery in eyes with high myopia (8 diopters or more). This study included 5 eyes (20.8\%) with axial lengths $\geq 30.0 \mathrm{~mm}$ and a rates of macular hole closure of $80 \%$ in these eyes compared to $89.5 \%$ in highly myopic eyes with axial lengths 27.1-29.1 mm. This result is not consistent with our study in terms of closure rates in highly myopic eyes with axial lengths $\geq 30.0 \mathrm{~mm}$. In contrast, the closure rate $(91.7 \%)$ of highly myopic eyes with axial lengths $26.0-30.0 \mathrm{~mm}$ in our study was not significantly low compared to the closure rate $(100 \%)$ of eyes with axial lengths $<26.0 \mathrm{~mm}$. This closure rate of highly myopic eyes with axial lengths $26.0-30.0 \mathrm{~mm}$ appears to be comparable with the closure rate $(89.5 \%)$ of eyes with axial lengths $27.1-29.1 \mathrm{~mm}$ in the study by Grucia-Arumi, et $\mathrm{al}^{23}$.

We should be careful when we compare our study with previous studies since subject inclusion in 3 of those 4 studies was made on the basis of refraction and not axial length. In addition, these previous studies differ from ours in that they did not include ILM peeling or use OCT to determine if the macular holes were closed. Especially in eyes with high myopia and chorioretinal atrophy, it is difficult to see on biomicroscopy examinations if the macular hole is actually closed. Serial B-scan imaging with SD-OCT over the macula ${ }^{24-27}$ can be expected to more precisely identify the presence of macular holes after surgeries in eyes with high myopia and chorioretinal atrophy, even when the macular hole is not evident on biomicroscopic examination as seen in Figure 4 of our study. It is possible that these differences in study design, particularly in the use of SD-OCT, warrant that our finding of axial length $\geq 30.0 \mathrm{~mm}$ is most associated with unsuccessful macular hole closure.

We found "retinoschisis-like" thickening of the outer retina, particularly in eyes with high myopia. This feature resembles retinal thickening seen in myopic macular retinoschisis (or myopic foveoschisis) in that the separation is widely seen over the macula ${ }_{1}^{33-36}$ but it is different from the typical tomographic features of idiopathic macular holes in which retinal thickening is limited to the vicinity of the fovea. ${ }^{37-42}$ However, the eyes in our study with this feature also had multiple cystoid spaces in the inner nuclear layer, which is a typical feature of macular hole but rarely occurs with myopic macular retinoschisis. 
The "retinoschisis-like" feature was seen in $67 \%$ of eyes with severely high myopia (axial lengths $\geq 30.0 \mathrm{~mm}$ ) compared to $16.7 \%$ of eyes with moderately high myopia (axial lengths $\geqq 26.0 \mathrm{~mm}$ and $<30.0 \mathrm{~mm}$ ) and $5.4 \%$ of eyes with axial lengths $<26.0 \mathrm{~mm}$. A larger number of patients are required to determine if axial length plays a role in the development of this pattern. This "retinoschisis-like" feature was significantly associated with anatomical failure of the macular hole surgery (75\%) and is likely predictive of anatomical failure of macular hole surgery in highly myopic eyes. Exploration of this point would also require a larger number of patients.

It is possible that some remaining traction after ILM peeling is responsible for the failed macular hole closure in eyes with axial lengths $\geq 30.0 \mathrm{~mm}$. This is suggested by the persistence or recurrence of retinoschisis-like thickening of the outer retina after ILM peeling. Possible sources of traction on the retina include the vitreous cortex, axial elongation, posterior staphyloma, the ILM, and retinal vessels in eyes with high myopia. ${ }^{35,36,43-48}$ Traction by the ILM should have been relieved by ILM peeling. ${ }^{45,47,49,50}$ However, remaining ILM, particularly ILM on the retinal vessels, ${ }^{45}$ may cause some traction. $\frac{51}{}$ In our study, we found posterior staphyloma in all 3 eyes with axial lengths $\geq 30.0 \mathrm{~mm}$. In eyes with axial lengths $\geq 26.0 \mathrm{~mm}$, posterior staphyloma was seen in $3(75 \%)$ of 4 eyes with failure compared to only $3(27.3 \%)$ of 11 eyes with success, although this difference was not statistically significant. It is possible that, as with myopic macular retinoschisis, ${ }^{29}$ traction in the posterior direction caused by severe axial elongation plus posterior staphyloma is associated with greater likelihood of failures of macular hole surgery. Exploration of this point would also require a larger number of patients.

A limitation of the current study is its retrospective design. We could not determine the actual extent of ILM peeling from chart reviews. In addition, serial B-scans on the same scan protocols were not available to allow us to determine whether the macular holes had closed.

In summary, our retrospective study found that in eyes with macular hole that were treated with PPV with ILM peeling and gas tamponade, initial or final closure of macular holes as confirmed by serial SD-OCT scans could not be achieved in any eyes with severely high myopia with axial lengths $\geq 30.0 \mathrm{~mm}$. The closure rate of highly myopic eyes with axial lengths $26.0-30.0$ $\mathrm{mm}$ was not significantly lower than that of eyes with axial lengths $<26.0 \mathrm{~mm}$. Further larger-scale investigations will be required to determine other prognostic factors in the surgical outcome of macular holes. 


\section{ACKNOWLEDGMENTS}

Funding/Support: This research was supported in part by a Grant-in-Aid for Scientific Research (20592038) from the Japan Society for the Promotion of Science (JSPS), Tokyo, Japan.

Financial Disclosure: Masanori Hangai is a paid advisory board member for NIDEK CO., LTD., and received consulting fees from Topcon Corporation, and Nagahisa Yoshimura is a paid advisory board member for NIDEK CO., LTD., and is a paid advisory board member for Topcon Corporation. Kenji Suda has no conflict of interest to disclose.

Contributions of Authors: Design of the study (KS, MH, NY); Data collection (KS); Analysis and interpretation (KS); Writing of the article (KS, MH); Critical revision of the article (NY); Final approval of the article (KS, MH, NY).

Statement about Conformity with Author Information: All investigations of this study adhered to the tenets of the Declaration of Helsinki. This study was approved by the Institutional Review Board and Ethics Committee of the Kyoto University Graduate School of Medicine. Informed consent was obtained for all patient examinations. 
Axial length and macular hole surgery. Suda K, et al._-Page 9

\section{REFERENCES}

1. Gass J. Idiopathic senile macular hole. Its early stages and pathogenesis. Arch Ophthalmol 1988;106(5):629-639.

2. Johnson RN, Gass JD. Idiopathic macular holes. Observations, stages of formation, and implications for surgical intervention. Ophthalmology 1988;95(7):917-924.

3. Gass JD. Reappraisal of biomicroscopic classification of stages of development of a macular

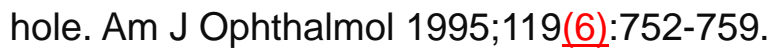

4. Smiddy WE, Flynn HW Jr. Pathogenesis of macular holes and therapeutic implications. Am J Ophthalmol 2004;137(3):525-537.

5. Kelly N, Wendel R. Vitreous surgery for idiopathic macular holes. Results of a pilot study. Arch Ophthalmol 1991;109(5):654-659.

6. Smiddy WE, Glaser BM, Thompson JT, et al. Transforming growth factor-beta 2 significantly enhances the ability to flatten the rim of subretinal fluid surrounding macular holes.

Preliminary anatomic results of a multicenter prospective randomized study. Retina 1993;13(4):296-301.

7. Wendel RT, Patel AC, Kelly NE, Salzano TC, Wells JW, Novack GD. Vitreous surgery for macular holes. Ophthalmology 1993;100(11):1671-1676.

8. Ryan EH Jr, Gilbert HD. Results of surgical treatment of recent-onset full-thickness idiopathic macular holes. Arch Ophthalmol 1994;112(12):1545-1553.

9. Freeman WR, Azen SP, Kim JW, el-Haig W, Mishell DR 3rd, Bailey I. Vitrectomy for the treatment of full-thickness stage 3 or 4 macular holes. Results of a multicentered randomized clinical trial. Vitrectomy for Treatment of Macular Hole Study Group. Arch Ophthalmol 1997;115(1):11-21.

10. de Bustros S. Vitrectomy for prevention of macular holes. Results of a randomized multicenter clinical trial. Vitrectomy for Prevention of Macular Hole Study Group. Ophthalmology 1994;101(6):1055-1059.

11. Rodrigues EB, Meyer $\mathrm{CH}$. Meta-analysis of chromovitrectomy with indocyanine green in macular hole surgery. Ophthalmologica 2008;222(2):123-129.

12. Kim JW, Freeman WR, Azen SP, el-Haig W, Klein DJ, Bailey IL. Prospective randomized trial of vitrectomy or observation for stage 2 macular holes. Vitrectomy for Macular Hole Study Group. Am J Ophthalmol 1996;121(6):605-614.

13. Roth DB, Smiddy WE, Feuer W. Vitreous surgery for chronic macular holes. Ophthalmology 1997;104(12):2047-2052.

14. Mester U, Becker M. Prognostic factors in surgery of macular holes. Ophthalmologe 1998;95(3):158-162. 
15. Kumagai K, Ogino N, Demizu S, et al. Factors related to initial success in macular hole surgery. Nippon Ganka Gakkai Zasshi 2000;104(11):792-796.

16. Gander IC, Senn P, Luthi M, Schipper I. Prognostic factors and results after surgical treatment of idiopathic macular holes, stage 2 and 3. Klin Monatsbl Augenheilkd 2000;216(5):272-277.

17. Ip MS, Baker BJ, Duker JS, et al. Anatomical outcomes of surgery for idiopathic macular hole as determined by optical coherence tomography. Arch Ophthalmol 2002;120(1):29-35.

18. Kang S, Ahn K, Ham D. Types of macular hole closure and their clinical implications. Br J Ophthalmol 2003;87(18):1015-1019.

19. Patel SC, Loo RH, Thompson JT, Sjaarda RN. Macular hole surgery in high myopia. Ophthalmology 2001;108(2):377-380.

20. Sulkes D, Smiddy W, Flynn H, Feuer W. Outcomes of macular hole surgery in severely myopic eyes: A case-control study. Am J Ophthalmol 2000;130(3):335-339.

21. Kobayashi H, Kobayashi K, Okinami S. Macular hole and myopic refraction. Br J Ophthalmol 2002;86(11):1269-1273.

22. García-Arumí J, Martinez V, Puig J, Corcostegui B. The role of vitreoretinal surgery in the management of myopic macular hole without retinal detachment. Retina 2001;21(4):332-338.

23. Coppé A, Ripandelli G, Parisi V, Varano M, Stirpe M. Prevalence of asymptomatic macular holes in highly myopic eyes. Ophthalmology 2005;112(12):2103-2109.

24. Schmidt-Erfurth U, Leitgeb RA, Michels S, et al. Three-dimensional ultrahigh-resolution optical coherence tomography of macular diseases. Invest Ophthalmol Vis Sci 2005;46(9):3393-3402.

25. Alam S, Zawadzki RJ, Choi S, et al. Clinical application of rapid serial Fourier-domain optical coherence tomography for macular imaging. Ophthalmology 2006;113(8):1425-1431.

26. Hangai M, Ojima Y, Gotoh N, et al. Three-dimensional imaging of macular holes with high-speed optical coherence tomography. Ophthalmology 2007;114(4):763-773.

27. Srinivasan VJ, Wojtkowski M, Witkin AJ, et al. High-definition and 3-dimensional imaging of macular pathologies with high-speed ultrahigh-resolution optical coherence tomography. Ophthalmology 2006;113(11):2054.e1-14.

28. Hangai M, Yamamoto M, Sakamoto A, Yoshimura N. Ultrahigh-resolution versus speckle noise-reduction in spectral-domain optical coherence tomography. Opt Express 2009;17(5):4221-4235.

29. Sakamoto T, Miyazaki M, Hisatomi T, Nakamura T, et al. Triamcinolone-assisted pars plana vitrectomy improves the surgical procedures and decreases the postoperative blood-ocular barrier breakdown. Graefes Arch Clin Exp Ophthalmol 2002;240(6):423-429. 
30. Kimura H, Kuroda S, Nagata M. Triamcinolone acetonide-assisted peeling of the internal limiting membrane. Am J Ophthalmol 2004;137(1):172-173.

31. Yamada E. Some structural features of the fovea centralis in the human retina. Arch Ophthalmol 1969;82(2):151-159.

32. Gass JD. Müller cell cone, an overlooked part of the anatomy of the fovea centralis: hypotheses concerning its role in the pathogenesis of macular hole and foveomacular retinoschisis. Arch Ophthalmol 1999;117(6):821-823.

33. Takano M, Kishi S. Foveal retinoschisis and retinal detachment in severely myopic eyes with posterior staphyloma. Am J Ophthalmol 1999;128(4):472-476.

34. Benhamou N, Massin P, Haouchine B, Erginay A, Gaudric A. Macular retinoschisis in highly myopic eyes. Am J Ophthalmol 2002;133(6):794-800.

35. Gaucher D, Haouchine B, Tadayoni R, et al. Long-term follow-up of high myopic foveoschisis: Natural course and surgical outcome. Am J Ophthalmol 2007;143(3):455-462.

36. Shimada N, Ohno-Matsui K, Yoshida T, Sugamoto Y, Tokoro T, Mochizuki M. Progression from macular retinoschisis to retinal detachment in highly myopic eyes is associated with outer lamellar hole formation. Br J Ophthalmol 2008;92(6):762-764.

37. Puliafito CA, Hee MR, Lin CP, et al. Imaging of macular diseases with optical coherence tomography. Ophthalmology 1995;102(2):217-229.

38. Hee MR, Puliafito CA, Wong C, et al. Optical coherence tomography of macular holes. Ophthalmology 1995;102(5):748-756.

39. Gaudric A, Haouchine B, Massin P, Paques M, Blain P, Erginay A. Macular hole formation: New data provided by optical coherence tomography. Arch Ophthalmol 1999;1176(6):744-751.

40. Haouchine B, Massin P, Gaudric A. Foveal pseudocyst as the first step in macular hole formation: A prospective study by optical coherence tomography. Ophthalmology 2001;108(1):15-22.

41. Kishi S, Takahashi $\mathrm{H}$. Three-dimensional observations of developing macular holes. Am J Ophthalmol 2000;130(1):65-75.

42. Kishi S, Kamei Y, Shimizu K. Tractional elevation of Henle's fiber layer in idiopathic macular holes. Am J Ophthalmol 1995;120(4):486-496.

43. Baba T, Ohno-Matsui K, Futagami S, et al. Prevalence and characteristics of foveal retinal detachment without macular hole in high myopia. Am J Ophthalmol 2003;135(3):338-342.

44. Bando H, Ikuno Y, Choi JS, Tano Y, Yamanaka I, Ishibashi T. Ultrastructure of internal limiting membrane in myopic foveoschisis. Am J Ophthalmol 2005;139(1):197-199.

45. Ikuno Y, Gomi F, Tano Y. Potent retinal arteriolar traction as a possible cause of myopic 
foveoschisis. Am J Ophthalmol 2005;139(3):462-467.

46. Sayanagi K, Ikuno Y, Tano Y. Macular hole diameter after vitrectomy for macular hole and retinal detachment. Retina 2005;25(5):608-611.

47. Sayanagi K, Ikuno $\mathrm{Y}$, Tano $\mathrm{Y}$. Reoperation for persistent myopic foveoschisis after primary vitrectomy. Am J Ophthalmol 2006;141(2):414-417.

48. Forte R, Cennamo G, Pascotto F, de Crecchio G. En face optical coherence tomography of the posterior pole in high myopia. Am J Ophthalmol 2008;145(2):281-288.

49. Kobayashi $\mathrm{H}$, Kishi S. Vitreous surgery for highly myopic eyes with foveal detachment and retinoschisis. Ophthalmology 2003;110(9):1702-1707.

50. Ikuno $\mathrm{Y}$, Tano $\mathrm{Y}$. Vitrectomy for macular holes associated with myopic foveoschisis. Am J Ophthalmol 2006;141(4):774-776.

51. Schumann RG, Rohleder M, Schaumberger MM, Haritoglou C, Kampik A, Gandorfer A. Idiopathic macular holes: Ultrastructural aspects of surgical failure. Retina 2008;28(2):340-349. 


\section{FIGURE CAPTIONS}

Figure 1. Linear regression of axial length in millimeters $(\mathrm{mm})$ against age $(r=-0.44 \underline{7}, P=0.001)$ for $5 \underline{2}$ eyes with macular holes treated surgically. White circles = eyes in which the initial surgery was successful. Black circles = eyes in which the initial surgery failed to close the hole.

Figure 2. Abnormal features in horizontal 9-mm-long B-scan images obtained by speckle-noise-reduced (averaging multiple B-scans at the same location) spectral-domain optical coherence tomography (left column, from top to bottom) in eyes with full-thickness macular holes and axial lengths $\leq 26.0 \mathrm{~mm}$. (Right column, from top to bottom) Color fundus photographs show, by green arrows, the direction of scanning to obtain images in (left column, from top to bottom), respectively. (Top) Stage 2 macular hole in the left eye of a 68-year-old man. (Middle) Stage 3 macular hole in the left eye of a 63-year-old woman. (Bottom) Stage 4 macular hole in the left eye of a 65-year-old woman. Abnormal features, shown by asterisks and white arrows, were cystoid spaces in the Henle nerve fiber layer and the inner nuclear layer, respectively, that were seen only in the vicinity of the fovea, in all scans, and retinal thickening, also limited to the vicinity of the fovea (left column, from top to bottom).

Figure 3. Images of the right eye of a 63-year-old woman with macular hole. Best-corrected visual acuity before surgery was $20 / 333$ and axial length was $26.7 \mathrm{~mm}$. (Top row left) A horizontal time-domain optical coherence tomography (OCT) B-scan obtained at the initial visit (Upper), and horizontal speckle-noise-reduced spectral-domain OCT images one month after the first operation (Lower). The image in (Top row left upper) is blurred, due to cataract, but shows a stage 4 full-thickness macular hole with apparent retinal thickening, mainly in the outer retina, that extends widely extrafoveally. (Top right) A color fundus photograph obtained one month after the first operation. The green (6-mm long) and white (9- $\mathrm{mm}$ long) arrows indicate the scan lines in (Top left) and in (Second row) and (Third row), respectively. (Second and third rows) Horizontal speckle-noise-reduced spectral-domain OCT images one year (Second row) after the first operation, and one month after the second surgery (Third row). One month after the first operation, the macular hole remained open but its edge was not elevated. At one year after the operation, the edge of the macular hole was lifted up and the retina was thickened over much of the macula. A second operation was therefore performed. One month after the second operation, the macular hole remained open and thickening of the retina in the macula persisted. (Bottom left and right), Magnified (2X) views of areas outlined by red dashed lines in the B-scan images in (Second row) and (Third row), respectively. Where the retina was thickened, columnar structures are seen in the "retinoschisis-like" separation between the outer plexiform 
layer and the outer nuclear layer. The extent of the "retinoschisis-like" feature is indicated by white double-headed arrows.

Figure 4. Images of the right eye of a 58-year-old woman with macular hole and posterior staphyloma. Best-corrected visual acuity before surgery was 20/125 and axial length was 31.89 mm. (Left) Horizontal 9-mm-long speckle-noise-reduced spectral domain optical coherence tomography images. (Right) Color fundus photographs. (Top) Four months before the first operation; retinal thickening was limited to the nasal retina. (Second row) Two months before the first operation, retinal thickening extended widely in the macula and a "retinoschisis-like" feature became evident in the macular region (white double-headed arrows). (Third row) One month after the first operation, the macular hole and "retinoschisis-like" feature (white double-headed arrows) were still present and retinal detachment appeared to have extended. (Bottom) 2 months after the second operation the macular hole was larger, the nasal retina appeared to have shrunk, and temporal retinal detachment had enlarged, but the "retinoschisis-like" feature had disappeared. 
TABLE 1. Factors Associated with Initial Success or Initial Failure of Macular Hole Surgery

\begin{tabular}{|c|c|c|c|c|}
\hline Factor & Initial Success & Initial Failure & $P$ value & All Eyes \\
\hline Number of eyes & 48 & $\underline{4}$ & & $\underline{52}$ \\
\hline $\begin{array}{l}\text { Patient age }(n=50), \text { years; } \\
\text { mean } \pm \text { SD (range) }\end{array}$ & $\begin{array}{c}63.4 \pm 8.9 \\
(34-82)\end{array}$ & $\frac{63.0 \pm 5.0}{(58-70)}$ & $\underline{0.70^{b}}$ & $\begin{array}{c}\frac{63.4}{(34-82)} \\
\end{array}$ \\
\hline Men/ Women & $20 / 28$ & $\underline{0 / 4}$ & $\underline{0.15^{c}}$ & $20 / 32$ \\
\hline Right eyes/Left eyes & $25 / 23$ & $\underline{3 / 1}$ & $\underline{0.62^{c}}$ & $\underline{28 / 24}$ \\
\hline $\begin{array}{l}\text { Axial length, mm } \\
\text { mean } \pm S D \text { (range) }\end{array}$ & $\begin{array}{c}24.2 \pm 1.87 \\
(21.1=28.1)\end{array}$ & $\frac{30.0 \pm 2.3}{(26.7-31.9)}$ & $\leq 0.0001^{b}$ & $\begin{array}{c}\underline{24.6} \\
\underline{(21.1-31.9)}\end{array}$ \\
\hline $\begin{array}{l}\text { Preop. refractive error, } \\
\text { diopters } \\
\text { mean } \pm \text { SD (range) }\end{array}$ & $\begin{array}{l}-2.36 \pm 4.41 \\
(4.4=-14.4)\end{array}$ & $\frac{-10.3 \pm 8.89}{(-2.5--18.5)}$ & $\underline{0.031^{b}}$ & $\begin{array}{c}\frac{-3.0 \pm 5.2}{(-18.5-4.4)} \\
\end{array}$ \\
\hline Macular hole II & 13 & $\underline{0}$ & $\underline{0.67^{c}}$ & $\underline{13}$ \\
\hline stage & 21 & $\underline{2}$ & & $\underline{23}$ \\
\hline IV & 14 & $\underline{2}$ & & $\underline{16}$ \\
\hline $\begin{array}{l}\text { Symptom duration, months } \\
\text { mean } \pm \text { SD (range) }\end{array}$ & $\begin{array}{l}3.1 \pm 2.6 \\
(0.5=12)\end{array}$ & $\frac{10.0 \pm 12.3}{(1-24)}$ & $\underline{0.39^{b}}$ & $\frac{3.5 \pm 4.0}{(0.5-24)}$ \\
\hline $\begin{array}{l}\text { Size of hole, relative to } \\
\text { "disc vein diameter" }\end{array}$ & $\begin{array}{l}4.0 \pm 1.6 \\
(1.2=9.7)\end{array}$ & $\begin{array}{l}5.8 \pm 1.4 \\
(4.7-7.4) \\
\end{array}$ & $\underline{0.056^{b}}$ & $\begin{array}{l}\frac{4.1 \pm 1.6}{(1.2-9.7)} \\
\end{array}$ \\
\hline $\begin{array}{l}\text { Preop. LogMAR BCVA } \\
\text { mean } \pm \text { SD (range) }\end{array}$ & $\begin{array}{c}0.60 \pm 0.33 \\
(0.046-1.40)\end{array}$ & $\begin{array}{c}0.89 \pm 0.36 \\
(0.398-1.222) \\
\end{array}$ & $\underline{0.11^{b}}$ & $\begin{array}{c}\frac{0.62 \pm 0.34}{(0.050-1.40)} \\
\end{array}$ \\
\hline $\begin{array}{l}\text { Postop. LogMAR BCVA }{ }^{a} \\
\text { mean } \pm \text { SD (range) }\end{array}$ & $\begin{array}{l}0.247 \pm 0.32 \\
(-0.18=1.05)\end{array}$ & $\begin{array}{r}0.87 \pm 0.42 \\
(0.40-1.40) \\
\end{array}$ & $\underline{0.0050^{b}}$ & $\begin{array}{r}0.30 \pm 0.36 \\
\underline{(-0.18-1.40)} \\
\end{array}$ \\
\hline \multicolumn{5}{|c|}{ Preop. OCT findings } \\
\hline Posterior staphyloma & 4 & $\underline{3}$ & $\underline{0.0060^{c}}$ & $\underline{7}$ \\
\hline $\begin{array}{l}\text { Retinoschisis-like } \\
\text { thickening }\end{array}$ & 3 & $\underline{3}$ & $\underline{0.0030^{c}}$ & $\underline{6}$ \\
\hline \multicolumn{5}{|c|}{$\begin{array}{l}{ }^{a} \text { LogMAR BCVA at } 6 \text { months after the last surgery; }{ }^{-b} \text { Mann Whitney U-test; } \stackrel{c}{ } \text { Fisher's exact test. } \\
\text { "disc vein diameter" = width ( } 150 \text { um }) \text { of the vein on the edge of the optic disc; LogMAR BCVA } \\
=\text { logarithm of the minimal angle of resolution for best-corrected visual acuity; OCT = optical } \\
\text { coherence tomography; Preop. = preoperative; Postop. = postoperative; SD = standard } \\
\text { deviation }\end{array}$} \\
\hline
\end{tabular}


TABLE 2. Outcomes and Factors of Macular Hole Surgery According to Axial Length

\begin{tabular}{|c|c|c|c|c|c|c|c|c|c|c|}
\hline & \multicolumn{3}{|c|}{ High Myopia } & \multirow{2}{*}{$\begin{array}{c}\text { Emmetropi } \\
\text { a/ Mild } \\
\text { Myopia/ } \\
\text { Hyperopia } \\
\text { (G3) } \\
\end{array}$} & \multirow[b]{2}{*}{$\frac{\text { Among }}{3 \text { Groups }}$} & \multicolumn{2}{|c|}{$P$ value $^{\underline{a}}$} & \multirow[b]{2}{*}{ G2 vs. G3 } & \multirow[b]{2}{*}{$\begin{array}{c}\begin{array}{c}\text { Total } \\
(\mathrm{G} 1+\mathrm{G} 2+ \\
\underline{\mathrm{G} 3})\end{array}\end{array}$} \\
\hline & & $\begin{array}{l}\frac{\text { Severely }}{\underline{\text { High }}} \\
\frac{\text { Myopia }}{\text { (G1) }}\end{array}$ & $\frac{\text { Moderately }}{\underline{\text { High }}} \frac{\text { Myopia }}{\frac{\text { (G2) }}{\text { (G) }}}$ & $\begin{array}{c}\stackrel{\text { All }}{(G 1+G 2)} \\
\underline{(G 1}\end{array}$ & & & G1 vs. G2 & G1 vs. G3 & & \\
\hline \multicolumn{2}{|c|}{ Axial length } & $\geqq 30.0 \mathrm{~mm}$ & $\begin{array}{l}\geqq 26.0 \mathrm{~mm} \\
\leq 30.0 \mathrm{~mm}\end{array}$ & $\geqq 26.0 \mathrm{~mm}$ & $<26.00 \mathrm{~mm}$ & & & & & \\
\hline \multicolumn{2}{|c|}{ Number of patients } & $\underline{3}$ & $\underline{10}$ & 13 & $\underline{36}$ & & & & & $\underline{49}$ \\
\hline \multicolumn{2}{|c|}{$\begin{array}{l}\text { Patient age, years } \\
\text { mean } \pm 1 \text { SD (range) }\end{array}$} & $\frac{63.3 \pm 6.1}{\underline{(58-70)}}$ & $\frac{54.2 \pm 9.4}{(34-70)}$ & $\begin{array}{c}56.0 \pm 9.4 \\
(34=70)\end{array}$ & $\frac{66.4 \pm 6.2}{(56-82)}$ & $\leq 0.0001^{c}$ & $\underline{0.232^{e}}$ & $\underline{0.800^{e}}$ & $\underline{0.002^{e}}$ & $\frac{63.4 \pm 8.60}{(34-82)}$ \\
\hline \multicolumn{2}{|c|}{ Men/ Women } & $\underline{0 / 3}$ & $\underline{3 / 7}$ & $3 / 10$ & $\underline{15 / 21}$ & $\underline{0.40^{d}}$ & & & & $\underline{18 / 31}$ \\
\hline \multicolumn{2}{|c|}{ Number of eyes } & $\underline{3}$ & $\underline{12}$ & 15 & $\underline{37}$ & & & & & $\underline{52}$ \\
\hline \multicolumn{2}{|c|}{ Right eyes/Left eyes } & $\underline{2 / 1}$ & $\underline{6 / 6}$ & $8 / 7$ & $\underline{20 / 17}$ & $\underline{1^{d}}$ & & & & $\underline{28 / 24}$ \\
\hline \multirow{3}{*}{$\begin{array}{c}\text { Macular } \\
\text { hole } \\
\text { stage }\end{array}$} & II & $\underline{0}$ & $\underline{4}$ & 4 & $\underline{9}$ & $\underline{0.66^{d}}$ & & & & $\underline{13}$ \\
\hline & III & 1 & $\underline{4}$ & 5 & $\underline{18}$ & & & & & $\underline{23}$ \\
\hline & IV & $\underline{2}$ & $\underline{4}$ & 6 & $\underline{10}$ & & & & & $\underline{16}$ \\
\hline \multicolumn{2}{|c|}{$\begin{array}{l}\text { Symptom duration, } \\
\text { months (range) }\end{array}$} & $\frac{10.0 \pm 12.3}{(1-24)}$ & $\begin{array}{c}\underline{3.3 \pm 2.2} \\
(0.75-6) \\
\end{array}$ & $\begin{array}{l}4.8 \pm 6.1 \\
(1=24)\end{array}$ & $\begin{array}{l}\frac{3.0 \pm 2.8}{(0.5-12)} \\
\underline{(0.5-12}\end{array}$ & $\underline{0.60^{c}}$ & & & & $\begin{array}{r}\frac{3.5 \pm 4.0}{(0.5-24)} \\
\end{array}$ \\
\hline \multicolumn{11}{|c|}{ Preoperative } \\
\hline \multicolumn{2}{|c|}{$\begin{array}{l}\text { Axial length, mm } \\
\text { mean } \pm S D \text { (range) }\end{array}$} & $\frac{31.0 \pm 0.9}{\frac{(30.1-}{\underline{31.9)}}}$ & $\frac{27.0 \pm 0.7}{\frac{(26.0-}{\underline{28.1)}}}$ & $\begin{array}{c}27.8 \pm 1.8 \\
(26.0= \\
31.9)\end{array}$ & $\frac{23.4 \pm 1.1}{\frac{(21.1-}{\underline{25.7)}}}$ & $\leq 0.0001^{c}$ & $\underline{0.019^{e}}$ & $\leq 0.005^{e}$ & $\leq 0.0001^{e}$ & $\frac{24.6 \pm 2.4}{\frac{(21.1-}{\underline{31.9)}}}$ \\
\hline \multicolumn{2}{|c|}{$\begin{array}{l}\text { Preop. refractive } \\
\text { power, diopters }\end{array}$} & $\frac{-7.9 \pm 9.2}{\frac{(-18.5-}{-2.5)}}$ & $\frac{-9.6 \pm 3.9}{\frac{(-17.4-}{-3.8)}}$ & $\begin{array}{c}-9.3 \pm 5.0 \\
(-18.5= \\
-2.5)\end{array}$ & $\frac{-0.4 \pm 2.3}{\underline{(-5.5-4.4)}}$ & $\leq 0.0001^{c}$ & $\underline{0.99^{e}}$ & $\underline{0.54^{e}}$ & $\leq 0.0001^{e}$ & $\begin{array}{c}-3.0 \pm 5.2 \\
\underline{(-18.5-4.4)} \\
\end{array}$ \\
\hline
\end{tabular}




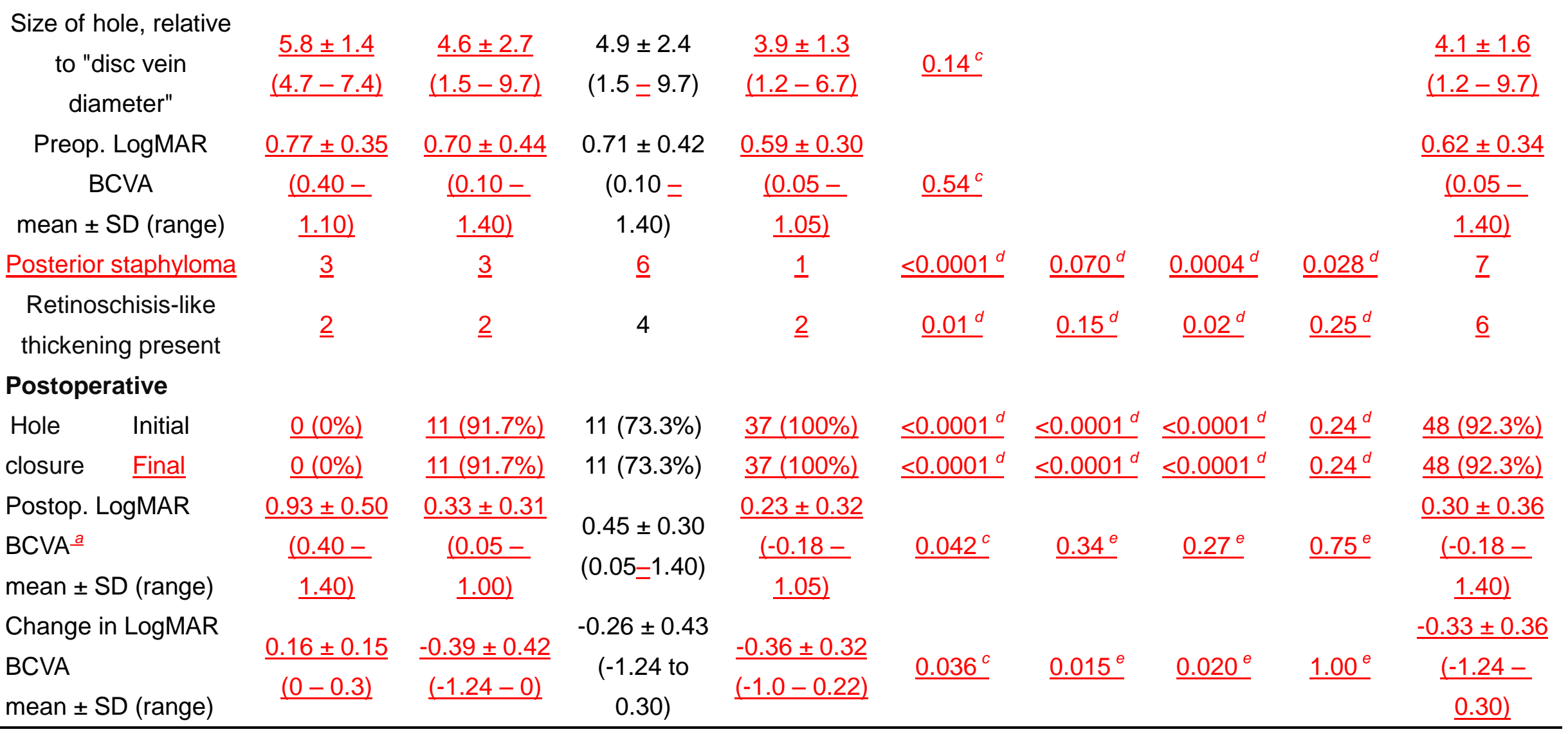

${ }^{a}$ LogMAR BCVA at 6 months after the last surgery

${ }^{b}$ Comparison was made among 3 groups

G1 = Group 1 (severely high myopia); G2 = Group 2 = moderately high myopia; G3 = Group 3 = emmetropia/mild myopia/hyperopia ${ }^{c}$ Kruskal Wallis H-test; ${ }^{d}$ Fisher's exact test; ${ }^{e}$ Dunnett's rank test

"disc vein diameter" = width ( $150 \mathrm{um})$ of the vein on the edge of the optic disc; LogMAR BCVA = logarithm of the minimal angle of resolution for best-corrected visual acuity; Preop. = preoperative; Postop. = postoperative; $\mathrm{SD}=$ standard deviation 
TABLE 3. Clinical Characteristics and SD-OCT Findings in 15 Eyes (15 Patients) with Moderate to High Myopia and Initial Failure or Success of Surgery

\begin{tabular}{|c|c|c|c|c|c|c|c|c|c|}
\hline Patient No. & $\begin{array}{l}\text { Age, } \\
\text { years }\end{array}$ & Gender & $\begin{array}{c}\text { Macular } \\
\text { Hole } \\
\text { Stage }\end{array}$ & Eye & $\begin{array}{l}\text { Axial Length } \\
(\mathrm{mm})\end{array}$ & $\begin{array}{c}\text { Symptom } \\
\text { Duration, } \\
\text { months }\end{array}$ & $\begin{array}{l}\text { Posterior } \\
\text { Staphyloma }\end{array}$ & $\begin{array}{l}\text { Retinoschisis-like } \\
\text { Feature (preop.) }\end{array}$ & $\begin{array}{l}\text { Retinoschisis-like } \\
\text { Feature (postop.) }\end{array}$ \\
\hline \multicolumn{10}{|l|}{ Initial Failure } \\
\hline 1 & 58 & $\mathrm{~F}$ & 4 & L & 31.9 & 5 & 1 & 1 & 1 \\
\hline 2 & 62 & $\mathrm{~F}$ & 4 & $\mathrm{R}$ & 31.2 & 1 & 1 & 0 & 1 \\
\hline 3 & 70 & $\mathrm{~F}$ & 3 & $\mathrm{R}$ & 30.1 & 24 & 1 & 1 & 0 \\
\hline 4 & 62 & $\mathrm{~F}$ & 3 & $\mathrm{R}$ & 26.7 & NA & 0 & 1 & 1 \\
\hline Mean or (\%) & 63 & $0 / 4(0)$ & & $1 / 4(25)$ & 30.0 & & $3 / 4(75)$ & $3 / 4(75)$ & $3 / 4(75)$ \\
\hline \multicolumn{10}{|c|}{ Initial Success } \\
\hline 5 & 34 & $\mathrm{~F}$ & 4 & L & 28.1 & 6 & 0 & 0 & 0 \\
\hline 6 & 63 & $\mathrm{~F}$ & 3 & $\mathrm{R}$ & 28.1 & 6 & 1 & 1 & 1 \\
\hline 7 & 43 & $\mathrm{~F}$ & 4 & L & 28.1 & 5 & 0 & 0 & 0 \\
\hline 8 & 50 & $M$ & 4 & L & 27.2 & 1 & 0 & 0 & 0 \\
\hline 9 & 49 & $M$ & 2 & $\mathrm{R}$ & 27.2 & 0.75 & 1 & 0 & 0 \\
\hline 10 & 58 & M & 3 & $L$ & 26.9 & 1 & 0 & 0 & 0 \\
\hline 11 & 53 & $\mathrm{~F}$ & 4 & $\mathrm{R}$ & 26.7 & 2 & 0 & 0 & 0 \\
\hline 12 & 62 & $\mathrm{~F}$ & 3 & $\mathrm{~L}$ & 26.5 & NA & 0 & 0 & 0 \\
\hline 13 & 66 & $\mathrm{~F}$ & 2 & L & 26.3 & 3 & 0 & 0 & 0 \\
\hline 14 & 59 & $M$ & 2 & $\mathrm{R}$ & 26.2 & 2 & 1 & 0 & 0 \\
\hline 15 & 51 & $\mathrm{~F}$ & 2 & $\mathrm{R}$ & 26 & 6 & 0 & 0 & 0 \\
\hline Mean or (\%) & 53.5 & $4 / 11(36.4)$ & & $6 / 11(54.5)$ & 27.0 & & $3 / 11(27.3)^{\star}$ & $1 / 11(9.1)^{*}$ & $1 / 11(9.1)^{*}$ \\
\hline$P$ value & $0.030^{*}$ & $1.0 \dagger$ & $0.36 \dagger$ & $0.57 \dagger$ & $0.056^{*}$ & $0.57^{*}$ & $0.24 \dagger$ & $0.033 \dagger$ & $0.033 \dagger$ \\
\hline
\end{tabular}

* Mann Whitney U-test; †Fisher's exact test

$\mathrm{F}$ = female; $\mathrm{L}$ = left eye; $\mathrm{M}$ = male; preop. = preoperative; postop. = postoperative; $\mathrm{R}$ = right eye; $\mathrm{SD}-\mathrm{OCT}=$ spectral-domain optical coherence tomography 


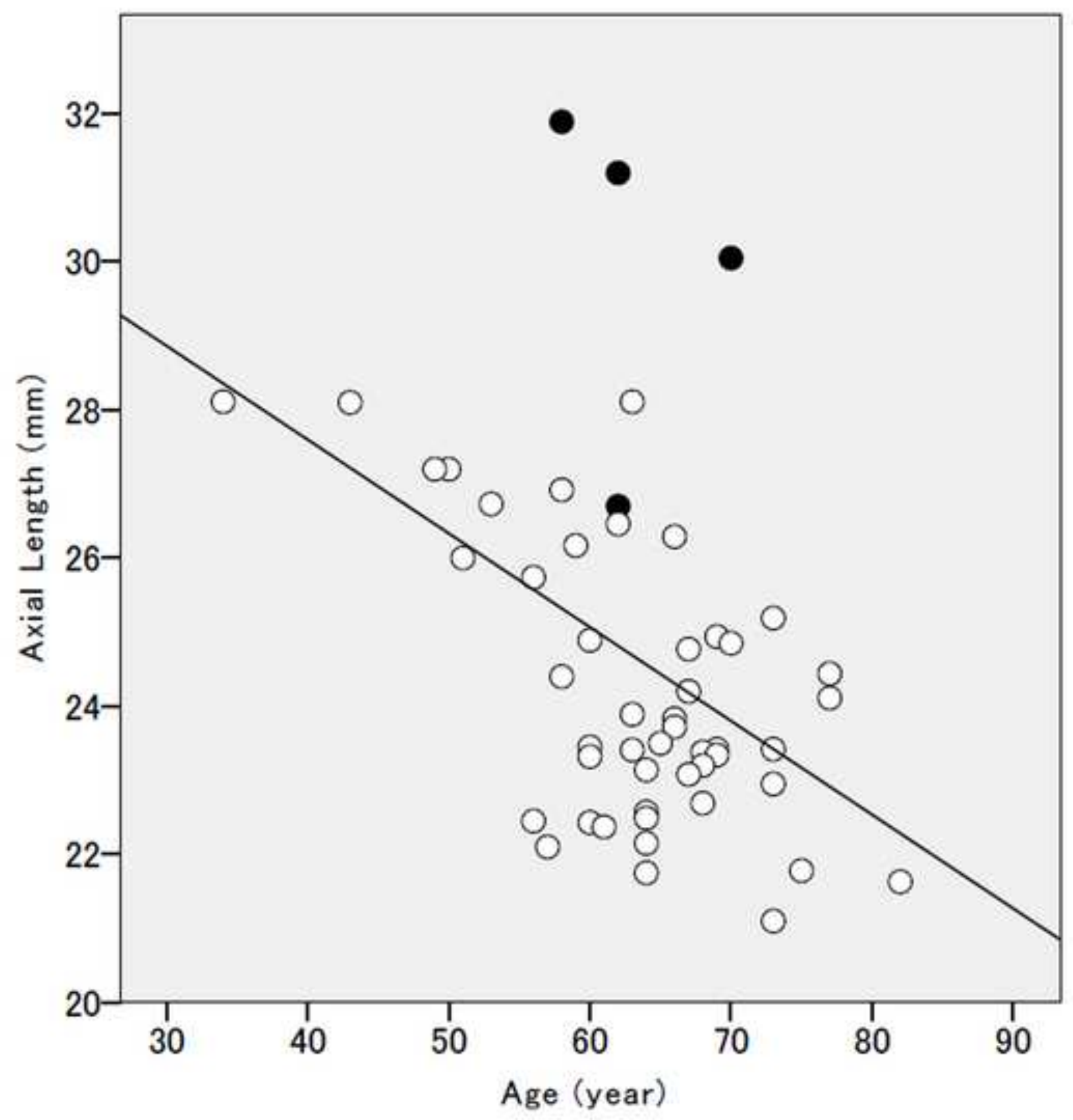


Click here to download high resolution image

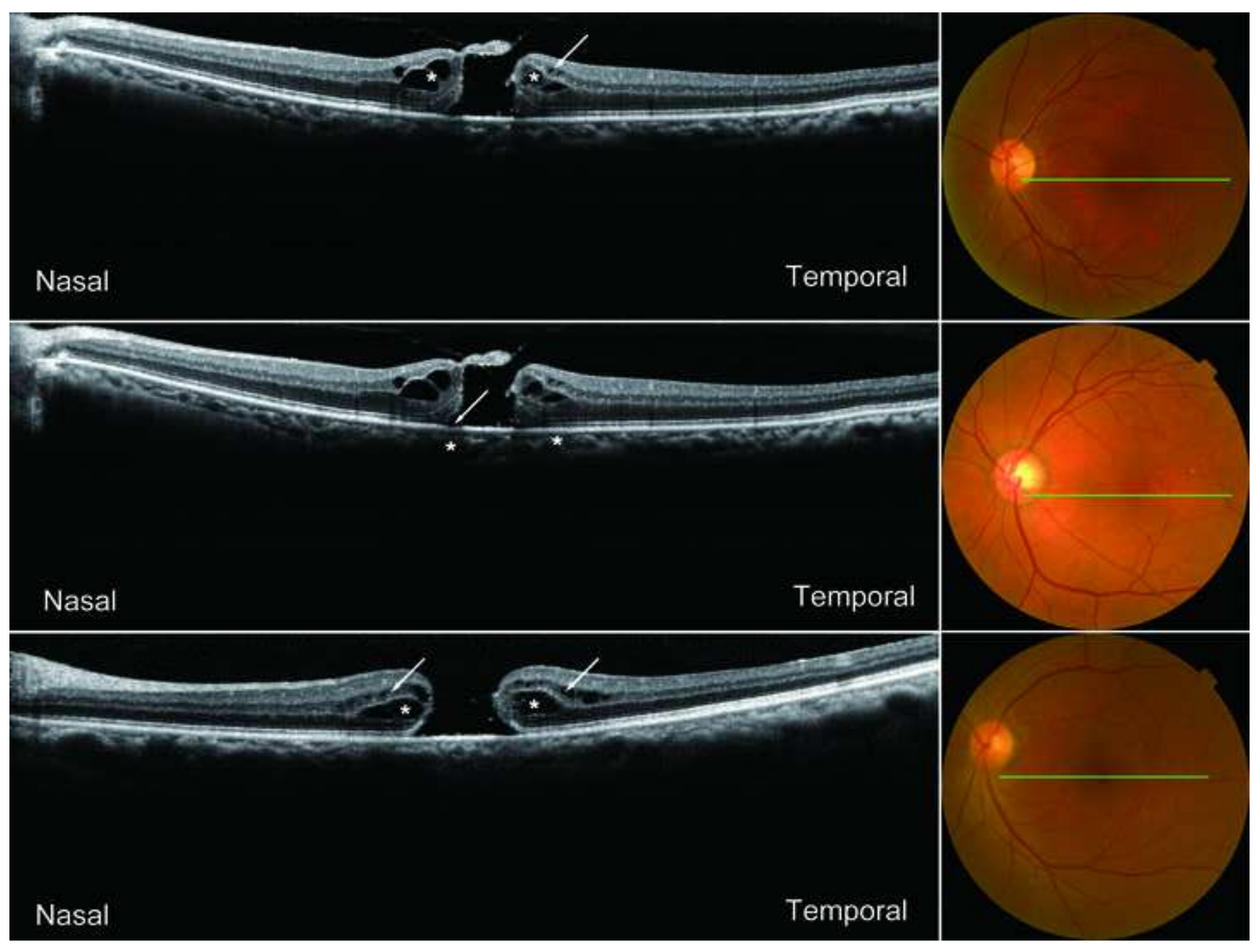

Nasal

Temporal

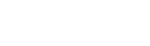

Temporal

Nasal

Temporal

Nasal

Temporal 
Click here to download high resolution image
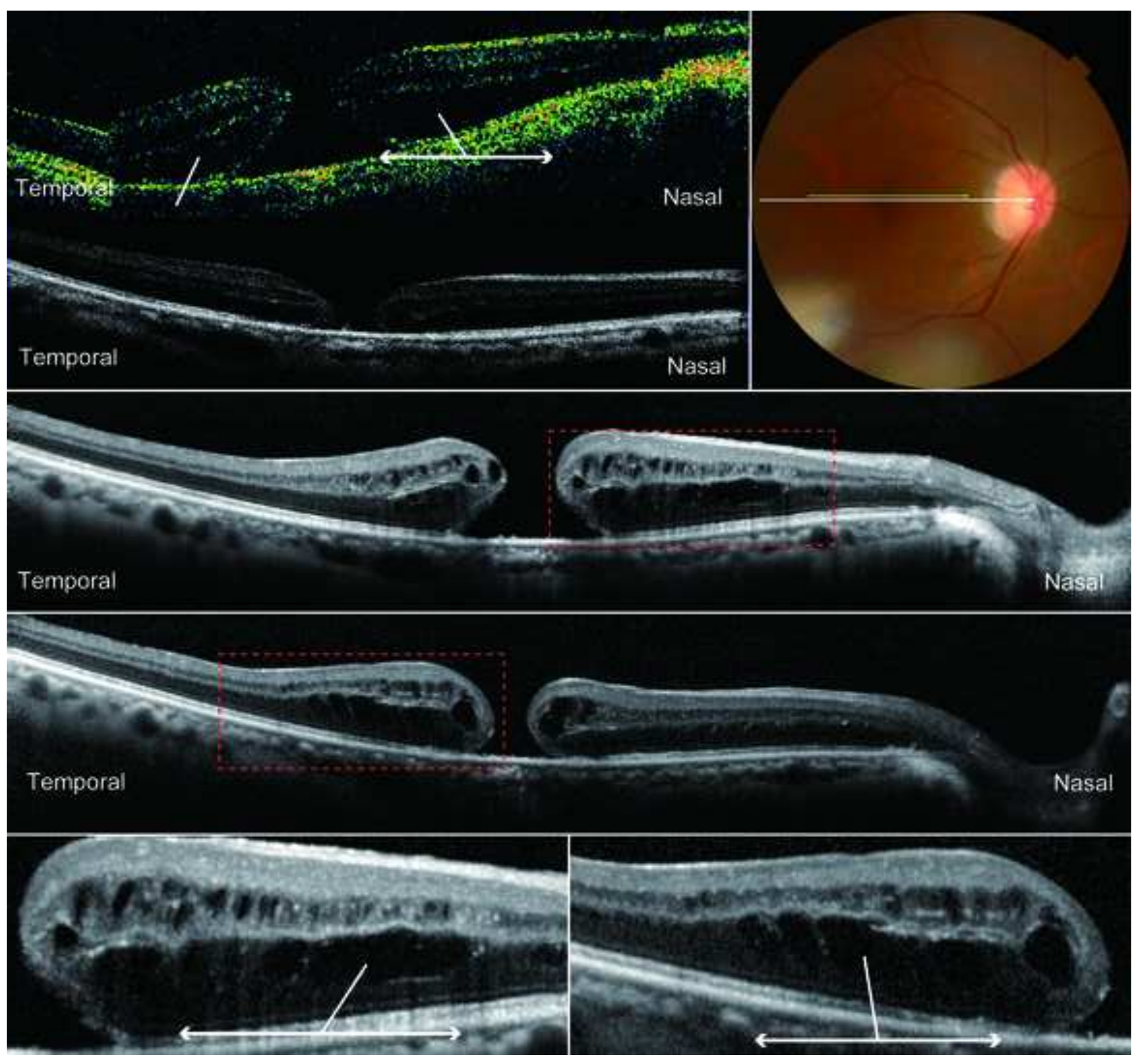
Table of Contents Statement

Re: AJO-10-155, "Axial Length and Outcomes of Macular Hole Surgery Assessed by Spectral-Domain Optical Coherence Tomography"

This retrospective study used SD-OCT macular scans to examine the surgical outcome of macular holes and found that they could not be closed in any of the highly myopic eyes with axial lengths $\geq 30.0 \mathrm{~mm}$. The closure rates of macular holes were not significantly low in highly myopic eyes with axial lengths $26.0-30.0 \mathrm{~mm}$ than in less myopic eyes with axial lengths $<26.0 \mathrm{~mm}$. 


\section{AJO Contributions of Authors and Sponsors}

\section{Manuscript Title Axial Length and Outcomes of Macular Hole Surgery Assessed by Spectral- Domain Optical Coherence Tomography}

\section{Authorship Responsibility and Contributions to Authorship}

The author byline should accurately reflect those that did the research and wrote the manuscript. Honorary or guest authors are not permitted. Medical writers or industry writers or statisticians may reach the level of authorship but at least should be listed in the Acknowledgement Section. There should be no ghost (hidden) authors. By submitting this manuscript, each author certifies that they have made a direct and substantial contribution to the work reported in the manuscript by participating in at least the following three areas: (1) conceiving and designing the study or analyzing and interpreting the data; (2) writing the manuscript or providing critical revisions that are important for the intellectual content; and (3) approving the final version of the manuscript. They have participated to a sufficient degree to take public responsibility for the work and believe that the manuscript describes truthful facts. They declare that they shall produce the data on which the manuscript is based for examination by the editors or their assignees, should it be requested. Each author also agrees to permit the corresponding author to make decisions regarding submission of the manuscript to the Journal, changes to galley proofs, and prepublication release of information in the manuscript to the media, federal agencies, or both. Galley proofs are to be approved by the corresponding author only.

By submitting this form, the corresponding author acknowledges that each author has read and completed 1) the statement on authorship responsibility and contribution to authorship and 2) the statement on sponsor involvement.

In the table below, please designate the substantive contribution(s) of each author. Any contribution not described in the box should be indicated in the space for "Other contributions." For a multicenter or group study, the authors listed on the title page should attest to this information but other members of the study group do not need to attest. However, they should be listed by name in an appendix. If the article is accepted, this information will appear as supplemental material at www.ajo.com.

\begin{tabular}{|c|c|c|c|c|c|c|c|c|c|c|c|}
\hline Author Name & 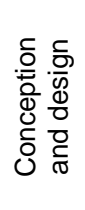 & 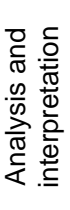 & 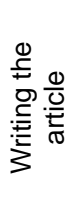 & 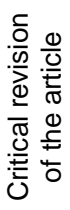 & 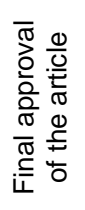 & 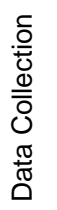 & 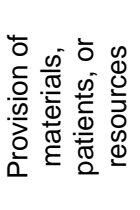 & 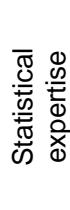 & 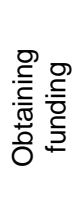 & 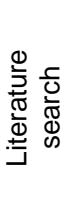 & 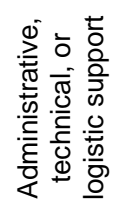 \\
\hline Kenji Suda & $\bigotimes$ & $\bigotimes$ & $\bigotimes$ & $\square$ & $\bigotimes$ & $\bigotimes$ & $\square$ & $\square$ & $\square$ & $\square$ & $\square$ \\
\hline Masanori Hangai & 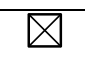 & $\square$ & $\nabla$ & $\square$ & 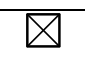 & $\square$ & $\square$ & $\square$ & 凶 & $\square$ & $\square$ \\
\hline \multirow[t]{8}{*}{ Nagahisa Yoshimura } & $\bigotimes$ & $\square$ & $\square$ & $\bigotimes$ & $\square$ & $\square$ & $\square$ & $\square$ & 凶 & $\square$ & $\square$ \\
\hline & $\square$ & $\square$ & $\square$ & $\square$ & $\square$ & $\square$ & $\square$ & $\square$ & $\square$ & $\square$ & $\square$ \\
\hline & $\square$ & $\square$ & $\square$ & $\square$ & $\square$ & $\square$ & $\square$ & $\square$ & $\square$ & $\square$ & $\square$ \\
\hline & $\square$ & $\square$ & $\square$ & $\square$ & $\square$ & $\square$ & $\square$ & $\square$ & $\square$ & $\square$ & $\square$ \\
\hline & $\square$ & $\square$ & $\square$ & $\square$ & $\square$ & $\square$ & $\square$ & $\square$ & $\square$ & $\square$ & $\square$ \\
\hline & $\square$ & $\square$ & $\square$ & $\square$ & $\square$ & $\square$ & $\square$ & $\square$ & $\square$ & $\square$ & $\square$ \\
\hline & $\square$ & $\square$ & $\square$ & $\square$ & $\square$ & $\square$ & $\square$ & $\square$ & $\square$ & $\square$ & $\square$ \\
\hline & $\square$ & $\square$ & $\square$ & $\square$ & $\square$ & $\square$ & $\square$ & $\square$ & $\square$ & $\square$ & $\square$ \\
\hline
\end{tabular}

Other contributions: 
None

\section{Sponsor Involvement}

Please describe in detail any involvement by a sponsor of this study in the design; collection, analysis, and interpretation of data; manuscript writing; and the decision to submit the manuscript for publication:

None

By submitting this manuscript, each of the authors indicate that they had full access to all of the data in this study and take complete responsibility for the integrity of the data and the accuracy of the data analysis.

As corresponding author, I certify that the above information is correct, and has been reviewed by each author.

Type your name (signature not required): Masanori Hangai

Please save this file as a Word document and upload to your manuscript submission. 


\section{AJO Author Disclosure Statement}

This form was adapted for the AJO from the New England Journal of Medicine.

Each author is required to fill out this form. The editor's interest extends to those areas relevant to the article that, broadly viewed, could be construed as constituting a conflict of interest or the appearance thereof. This form should be submitted at the time of the initial submission of the manuscript. The information will be used only by the Editorial Board of the AJO. It will not appear in print or on the AJO website. The footnote of the manuscript should still contain a short disclosure statement about each author.

If there is nothing to disclose, please so indicate.

Name Kenji Suda E-Mail qwm04525@kuhp.kyoto-u.ac.jp

Manuscript Title Axial Length and Outcomes of Macular Hole Surgery Assessed by Spectral-Domain Optical Coherence Tomography

Consulting fees or paid advisory boards (per year, for the past two years or the known future)

Entity

None $\quad \leq$ USD 10,000

$>\operatorname{USD} 10,000$

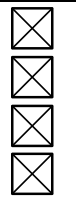

Equity ownership/stock options (publicly or privately traded firms, excluding mutual funds)

Entity

None $\quad \leq$ USD 10,000

$>$ USD 10,000

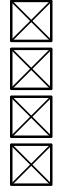

Lecture fees when speaking at the invitation of a commercial sponsor (per year, for the past two years or the known future)

Entity

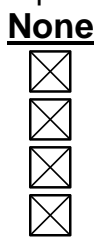

$\leq$ USD 10,000

$>$ USD 10,000

Are you employed by the commercial entity that sponsored the study? Yes $\square$ No $\square$

Grant support from industry? If yes complete next section. If none, indicate here: None $\square$

Current grant support. (include nonprofit/government entities):

Entity

Total Amount

Years Covered

Do you have patents and/or royalties, serve as an expert witness, or perform other activities for a commercial sponsor? Please provide a brief description:

None

Type your name (signature not required):Kenji Suda Date:2/19/2010 
Please save this file as a Word document and upload to your manuscript submission. A disclosure form is required for each author. 


\section{AJO Author Disclosure Statement}

This form was adapted for the AJO from the New England Journal of Medicine.

Each author is required to fill out this form. The editor's interest extends to those areas relevant to the article that, broadly viewed, could be construed as constituting a conflict of interest or the appearance thereof. This form should be submitted at the time of the initial submission of the manuscript. The information will be used only by the Editorial Board of the AJO. It will not appear in print or on the AJO website. The footnote of the manuscript should still contain a short disclosure statement about each author.

If there is nothing to disclose, please so indicate.

Name Masanori Hangai E-Mail hangai@kuhp.kyoto-u.ac.jp

Manuscript Title Axial Length and Outcomes of Macular Hole Surgery Assessed by Spectral-Domain Optical Coherence Tomography

Consulting fees or paid advisory boards (per year, for the past two years or the known future)

Entity

TOPCON

NIDEK

$\begin{array}{cc}\frac{\text { None }}{\square} & \leq \text { USD } 10,000 \\ 1,000 \\ \square & 10,000 \\ \square & \end{array}$

$>$ USD 10,000

Equity ownership/stock options (publicly or privately traded firms, excluding mutual funds)

Entity

None $\leq$ USD 10,000

$>\operatorname{USD} 10,000$

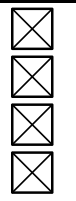

Lecture fees when speaking at the invitation of a commercial sponsor (per year, for the past two years or the known future)

Entity

$\frac{\text { None }}{\square}$

Are you employed by the commercial entity that sponsored the study? Yes $\square$ No $\square$

Grant support from industry? If yes complete next section. If none, indicate here: None $\square$

Current grant support. (include nonprofit/government entities):

Entity

a Grant-in-Aid for Scientific Research (20592038)

from the Japan Society for the Promotion of

Science (JSPS)

Do you have patents and/or royalties, serve as an expert witness, or perform other activities for a commercial sponsor? Please provide a brief description:

None 
Please save this file as a Word document and upload to your manuscript submission. A disclosure form is required for each author. 


\section{AJO Author Disclosure Statement}

This form was adapted for the AJO from the New England Journal of Medicine.

Each author is required to fill out this form. The editor's interest extends to those areas relevant to the article that, broadly viewed, could be construed as constituting a conflict of interest or the appearance thereof. This form should be submitted at the time of the initial submission of the manuscript. The information will be used only by the Editorial Board of the AJO. It will not appear in print or on the AJO website. The footnote of the manuscript should still contain a short disclosure statement about each author.

\section{If there is nothing to disclose, please so indicate.}

Name Nagahisa Yoshimurai E-Mail nagaeye@kuhp.kyoto-u.ac.jp

Manuscript Title Axial Length and Outcomes of Macular Hole Surgery Assessed by Spectral-Domain Optical Coherence Tomography

Consulting fees or paid advisory boards (per year, for the past two years or the known future)

Entity TOPCON NIDEK

$\begin{array}{cc}\frac{\text { None }}{\square} & \leq \text { USD } 10,000 \\ 2000 & 10,000 \\ \square & \\ \square & \end{array}$

None

X
$>\operatorname{USD} 10,000$

$>$ USD 10,000

Equity ownership/stock options (publicly or privately traded firms, excluding mutual funds)

Entity

None $\quad \leq$ USD 10,000

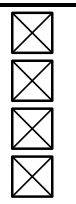

Lecture fees when speaking at the invitation of a commercial sponsor (per year, for the past two years or the known future)

Entity

$\frac{\text { None }}{\square}$

Are you employed by the commercial entity that sponsored the study? Yes $\square$ No $\square$

Grant support from industry? If yes complete next section. If none, indicate here: None $\square$

Current grant support. (include nonprofit/government entities):

Entity

Scientific Research(21249084)from the Japan

Society for the Promotion of Science(JSPS)

Grant from New Energy and Industrial

Technology Development Organization

Grant (Innovative Techno-Hub for Integrated

Medical Bio-imaging) from Japan Science and

$\leq$ USD 10,000

$>$ USD 10,000

Technology Agency

Do you have patents and/or royalties, serve as an expert witness, or perform other activities for a commercial sponsor? Please provide a brief description:

None 
Type your name (signature not required):Nagahisa Yoshimura Date:2/19/2010

Please save this file as a Word document and upload to your manuscript submission. A disclosure form is required for each author. 


\section{Biosketch}

Kenji Suda, MD, graduated from Kyoto University Medical School, Kyoto, Japan, in 2006. He completed his junior residency at Kyoto University Hospital and in the Department of Ophthalmology and Visual Sciences at Kyoto University Graduate School of Medicine. He currently serves as a senior ophthalmology resident at Hidaka Medical Center. 
E-

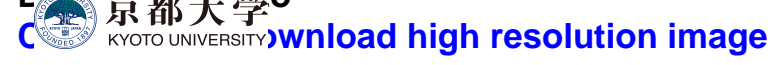

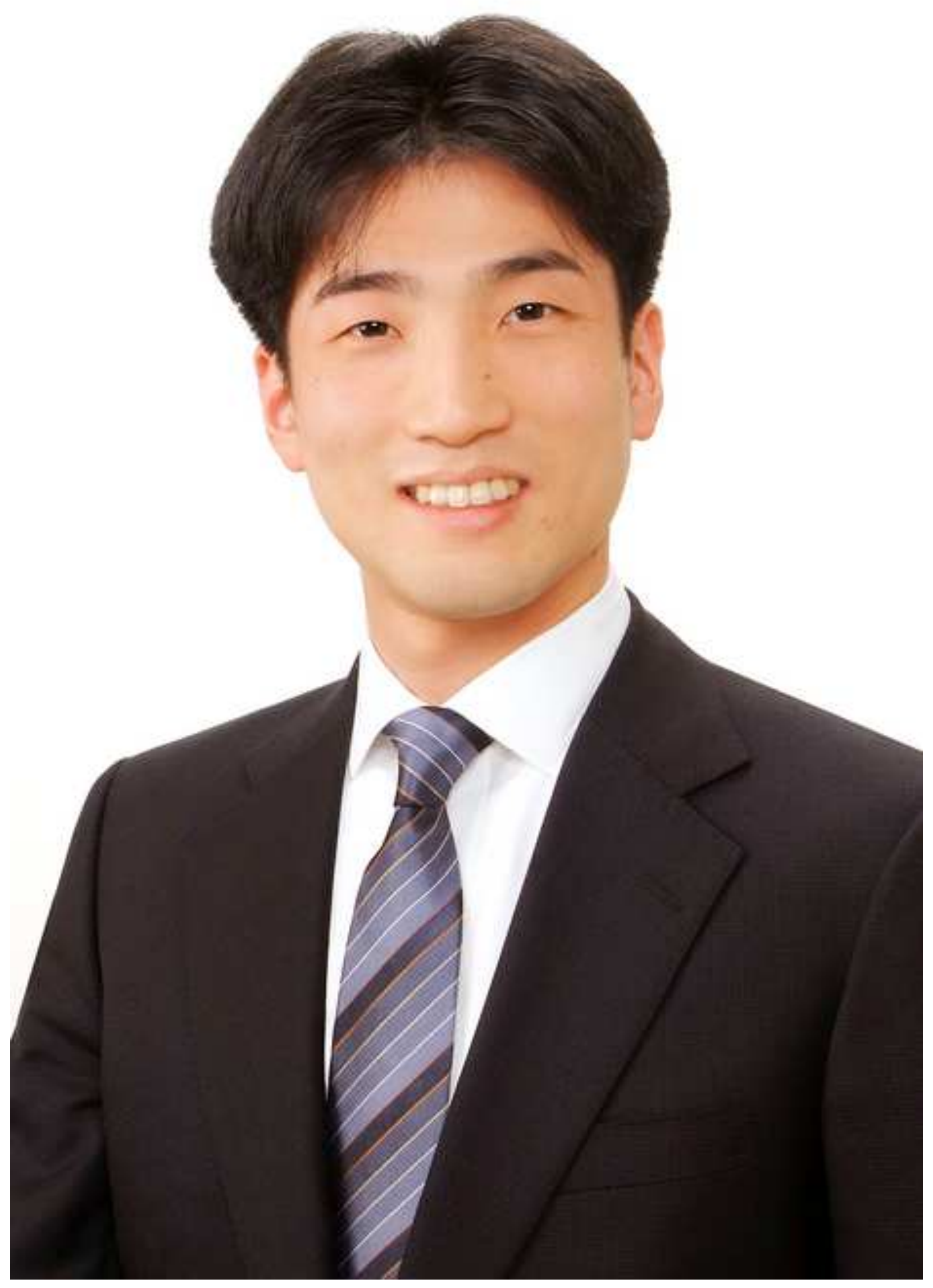

